\title{
Somatostatin Inhibition of Hippocampal CA1 Pyramidal Neurons: Mediation by Arachidonic Acid and Its Metabolites
}

\author{
Paul Schweitzer, ${ }^{1}$ Samuel Madamba, ${ }^{1}$ Jean Champagnat, ${ }^{2}$ and George Robert Siggins' \\ 'The Scripps Research Institute, Department of Neuropharmacology, La Jolla, California 92037 and ${ }^{2}$ Institut Alfred \\ Fessard, CNRS, 91190 Gif-sur-Yvette, France
}

\begin{abstract}
We used electrophysiological methods in a slice preparation to study the mechanisms of somatostatin (SS) effects on hippocampal pyramidal neurons. SS hyperpolarizes hippocampal pyramidal neurons in part by augmenting the timeand voltage-dependent $M$-current $\left(I_{M}\right)$, which has been shown to be reduced by muscarinic agonists. The SS effects are abolished by the phospholipase $A_{2}$ inhibitors 4-bromophenacyl bromide and quinacrine. Arachidonic acid (AA) mimics all the effects of SS on hippocampal pyramidal neurons. The effects of $A A$ and $S S$ on $I_{M}$ are blocked by the lipoxygenase inhibitor nordihydroguaiaretic acid but not by the cyclooxygenase inhibitor indomethacin. Prostaglandins $E_{2}, F_{2 \alpha}$, and $I_{2}$ do not increase $I_{w}$. However, the specific 5-lipoxygenase inhibitors 5,6-methanoleukotriene $A_{4}$ methylester and 5,6-dehydroarachidonic acid both blocked the $I_{M}$-augmenting action of either SS or AA. Leukotriene $C_{4}$ (but not leukotriene $B_{4}$ ) increases $I_{m}$ to the same extent as AA. $I_{M}$ was not altered by the 12-lipoxygenase product 12-hydroperoxyeicosatetraenoic acid, and SS effects were not altered by the 12-lipoxygenase inhibitor baicalein. These data implicate 5-lipoxygenase metabolite(s) (probably leukotriene $C_{4}$ ) as a mediator for the $I_{M}$-augmenting effect of $S S$. In addition, when the $I_{m}$ effect is blocked by lipoxygenase inhibitors, both SS and AA elicit another outward current that is not blocked by either lipoxygenase or cyclooxygenase inhibitors, suggesting a direct role of AA itself distinct from the $I_{M}$ effect. SS did not alter significantly $\mathrm{Ca}^{2+}$-dependent action potentials or, in whole-cell recordings, inward currents likely to represent high-threshold $\mathrm{Ca}^{2+}$ currents. The combined results of these studies suggest that SS hyperpolarizes hippocampal neurons by two mechanisms, both mediated through the AA system. However, one mechanism $\left(I_{M}\right)$ involves a metabolite of AA and is most effective at slightly depolarized potentials, whereas the other may involve AA itself and be more effective at membrane potentials near rest.
\end{abstract}

[Key words: hippocampus, somatostatin, arachidonic acid, phospholipase $A_{2}, M$-current, lipoxygenase, leukotrienes, voltage clamp]

\footnotetext{
Received June 9, 1992; revised Nov. 9, 1992; accepted Nov. 17, 1992.

We thank Nancy Callahan for typing the manuscript and Drs. F. E. Bloom and L. Chavez-Noriega for providing valuable criticism. This work was supported by grants from NIMH (MH 47680), NIAAA (AA 06420), and NATO.

Correspondence should be addressed to P. Schweitzer, CVN12, The Scripps Research Institute, 10666 North Torrey Pines Road, La Jolla, CA 92037.

Copyright (C) 1993 Society for Neuroscience $0270-6474 / 93 / 132033-17 \$ 05.00 / 0$
}

Somatostatin (SS; also SS-14, SRIF) is reported to be the second or third most abundant neuropeptide in most mammalian brain regions (Crawley, 1985). In hippocampus, immunohistochemical studies have revealed many SS-containing interneurons and a profuse network of intrinsic and extrinsic SS-containing fibcrs that appear to project to pyramidal and granule neurons (see, e.g., Bakst et al., 1986; Joëls et al., 1990). In addition, behavioral and clinical findings suggest an important role for SS in cognitive functions (Epelbaum, 1986). In spite of the apparent importance of SS in brain function, little is known of the exact physiological mechanisms of SS action. Results of early electrophysiological studies seemed to support a role for SS as an excitatory transmitter (Dodd and Kelly, 1978). However, more recent in vivo and in vitro studies in our laboratory (Pittman and Siggins, 1981; Mancillas et al., 1986; Moore et al., 1988; Schweitzer et al., 1990) and elsewhere (Watson and Pittman, 1988) support the view that SS is predominantly an inhibitory transmitter in the hippocampus. The inhibition of spike discharge is accompanied by a hyperpolarization associated with an increase in conductance to $\mathrm{K}^{+}$ions, at least in part via augmentation of the M-current $\left(I_{\mathrm{M}}\right)$ (Moore et al., 1988; Watson and Pittman, 1988; Schweitzer et al., 1990). SS also hyperpolarizes neurons in other brain areas by $\mathrm{K}^{+}$mechanisms (Inoue et al., 1988; Jacquin et al., 1988; Twery and Gallagher, 1989; Wang et al., 1989). Whereas SS-28, thought to be the preprohormone for SS-14, can act like SS-14 in some brain regions (Siggins et al., 1982; Jacquin et al., 1988; Moore et al., 1988; Watson and Pittman, 1988), in others SS-28 elicits responses different from, or even opposite to (Wang et al., 1989), those evoked by SS- 14 .

The $I_{\mathrm{M}}$ is a time- and voltage-dependent $\mathrm{K}^{+}$current that persists at slightly depolarized membrane potentials and is thought to clamp the membrane at potentials near rest (Brown and Adams, 1980; Adams et al., 1982). $I_{\mathrm{M}}$ is reduced by muscarinic cholinergic agonists, certain peptides (e.g., leutinizing hormone-releasing hormone, substance $\mathrm{P}$, bradykinin; for review, see Brown, 1988), 5-HT, and the excitatory amino acid quisqualate (Charpak et al., 1990), and by this mechanism is responsible in part for the slow and late-slow EPSPs in sympathetic neurons (Adams and Brown, 1982). Hippocampal pyramidal neurons also exhibit an $I_{\mathrm{M}}$, which may be responsible, at least in part, for the slow muscarinic EPSP evoked in hippocampal neurons by short stimulus trains (Halliwell and Adams, 1982; but see Madison et al., 1987). Recently, we reported that $I_{\mathrm{M}}$ in hippocampal neurons in vitro was not only reduced by muscarinic agonists but markedly augmented by SS, suggesting that two different receptors can reciprocally regulate one neuronal channel type (Moore et al., 1988). A similar reciprocal 


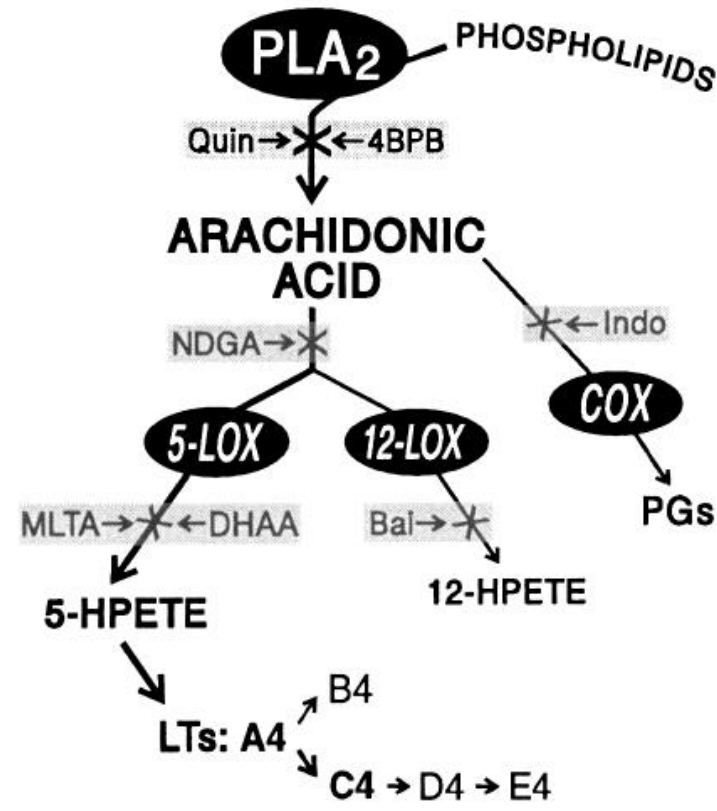

Figure 1. Schematic of AA metabolism. Phospholipid degradation by $\mathrm{PLA}_{2}$ leads to AA formation. AA can then be transformed through different enzymatic pathways to an array of metabolites, such as $P G S$ (prostaglandins), 5-HPETE and 12-HPETE (5- and 12-hydroperoxyeicosatetraenoic acid), and $L T s$ (leukotrienes $\mathrm{A}_{4}, \mathrm{~B}_{4}, \mathrm{C}_{4}, \mathrm{D}_{4}$, and $\mathrm{E}_{4}$ ). The different enzymes involved are $P L A_{2}$ (phospholipase $\mathrm{A}_{2}$ ), $C O X$ (cyclooxygenase), and 5-LOX and 12-LOX (5- and 12-lipoxygenase). (The cytochrome P-450 system is not shown for clarity.) The inhibitors used are $4 B P B$ (4-bromophenacyl bromide), Quin (quinacrine), $N D G A$ (nordihydroguaiaretic acid), Indo (indomethacin), Bai (baicalein), MLTA (5,6-methanoleukotriene $\mathrm{A}_{4}$ methylester), and DHAA (5,6-dehydroarachidonic acid) (for details on the drugs used and their specificity, see Blackwell and Flower, 1983; Higgs and Vane, 1983; Piomelli and Greengard, 1990).

$I_{\mathrm{M}}$ regulation, by $\mathrm{ACh}$ and isoproterenol, has been reported for smooth muscle cells (Sims et al., 1988).

The slow time course of SS-induced inhibitions and its ability to modulate GTP-binding proteins (North, 1989; Law et al., 1991) and the levels of second messengers (Schonbrunn, 1990) suggest involvement of some specific transduction systems in hippocampal SS effects. In sympathetic neurons, muscarinic reduction of $I_{\mathrm{M}}$ may be mediated through G-protein activation of phospholipase $C$ (PLC), with subsequent generation of diacylglycerols and activation of protein kinase $\mathrm{C}$ (Brown et al., 1989). By contrast, in hippocampal CAl pyramidal neurons muscarinic inactivation of $I_{\mathrm{M}}$ may not require protein kinase C activation (Malenka et al., 1986), but rather the inositol triphosphate side of the PLC cycle (Dutar and Nicoll, 1988). Another candidate for transduction is the cAMP system. Sims et al. (1988) recently showed that the augmentation of $I_{\mathrm{M}}$ by isoproterenol involves cAMP mediation in smooth muscle cells, and SS is known to modulate adenylate cyclase activity in brain (Chneiweiss et al., 1985; Wang et al., 1989).

The phospholipase $\mathrm{A}_{2}\left(\mathrm{PLA}_{2}\right)$ pathway (Fig. 1) is another source of mediators implicated in neuronal signal transduction (Piomelli et al., 1987a). This enzyme catalyzes the release of arachidonic acid (AA), yielding several eicosanoids via different metabolic pathways. Two major pathways for AA metabolism are (1) via cyclooxygenase (COX) to form prostanoids, and (2) via lipoxygenases (LOXs) to form hydroperoxyeicosatetraenoic acids (Needleman et al., 1986). Some 12-lipoxygenase (12-LOX) products mediate or modulate the effects of the peptides FMRFamide and histamine on $\mathrm{K}^{+}$channels in Aplysia neurons (Piomelli et al., 1987a,b), and hyperpolarize hippocampal pyramidal neurons (Carlen et al., 1989; Pace-Asciak et al., 1990). Metabolites of the 5-lipoxygenase (5-LOX) pathway alter spontaneous extracellular firing rate in rat cerebellar Purkinje cells in vivo (Palmer et al., 1981) and are involved in the opening of a G-protein-gated muscarinic $\mathrm{K}^{+}$channel $\left(I_{\mathrm{K} . \mathrm{ACh}}\right)$ in atrial cells (for reviews, see Piomelli and Greengard, 1990; Shimizu and Wolfe, 1990). AA itself and certain fatty acids also directly modulate $\mathrm{K}^{+}$and other conductances in peripheral tissues (reviewed by Ordway et al., 1991).

We recently reported data suggesting that an AA metabolite, perhaps a leukotriene, mediates the $I_{\mathrm{M}}$-augmenting effects of SS in hippocampal pyramidal cells (Schweitzer et al., 1990). In the present studies, we report new data suggesting another hyperpolarizing action of SS possibly mediated by AA itself, and we confirm the involvement of 5-LOX metabolites in $I_{\mathrm{M}}$ augmentation. In addition, we now find little evidence for the effects of $\mathrm{SS}$ on other $\mathrm{K}^{+}$conductances or on large inward currents in rat hippocampal pyramidal neurons.

\section{Materials and Methods}

Slice preparation. We used standard intracellular and whole-cell patchclamp recording techniques in the rat hippocampal slice, prepared as described previously (Pittman and Siggins, 1981; Moore et al., 1990). In brief, transverse hippocampal slices (taken from male Sprague-Dawley rats of 100-170 gm body weight) $350-400 \mu \mathrm{m}$ thick were cut on a brain slicer and incubated in gassed $\left(95 \% \mathrm{O}_{2}, 5 \% \mathrm{CO}_{2}\right)$ artificial cerebrospinal fluid (ACSF) of the following composition (in mM): $\mathrm{NaCl}$, $130 ; \mathrm{KCl}, 3.5 ; \mathrm{NaH}_{2} \mathrm{PO}_{4}, 1.25 ; \mathrm{MgSO}_{4} \cdot 7 \mathrm{H}_{2} \mathrm{O}, 1.5 ; \mathrm{CaCl}_{2}, 2.0 ; \mathrm{NaHCO}_{3}$, 24; glucose, 10. Other ions and agents were added to this ACSF medium. After a short incubation period in an interface configuration, the slices were completely submerged and continuously superfused with warm $\left(30-31^{\circ} \mathrm{C}\right) \mathrm{ACSF}$ at a constant rate within the range of $2.0-4.0 \mathrm{ml} / \mathrm{min}$. However, in five of nine cells studied with the leukotrienes, the flow rate was decreased to about $1-1.5 \mathrm{ml} / \mathrm{min}$ to ensure drug penetration into the slice, because their costliness dictated the use of small volumes. In this case, the slower flow rate was held constant throughout the recording period. The voltage-clamp studies were done at $30-31^{\circ} \mathrm{C}$ to slow down $I_{M}$ kinetics; however, in a previous study, SS superfusion at $35-37^{\circ} \mathrm{C}$ elicited the same augmenting effect on $I_{\mathrm{M}}$ as at lower temperatures (Moore et al., 1988). In most studies, we used sharp glass micropipettes filled with $\mathrm{KCl}(3 \mathrm{M}$; tip resistances, $50-80 \mathrm{M} \Omega$ ) to penetrate CA1 pyramidal neurons. Methods of superfusion, voltage-clamp recording, cell identification, drug administration, and data analysis were as described previously (Pittman and Siggins, 1981; Moore et al., 1988, 1990; Schweitzer et al., 1990).

Electrophysiological methods. Current- and voltage-clamp studies were performed with an Axoclamp preamplifier. In voltage-clamp mode, tetrodotoxin $(0.5-1 \mu \mathrm{M})$ was added to block synaptic transmission and $\mathrm{Na}^{+}$-dependent action potentials. In discontinuous single-electrode voltage-clamp mode, the switching frequency between current injection and voltage sampling was $3-4 \mathrm{kHz}$ for intracellular recording. Electrode "settling time" and input capacitance neutralization at the headstage were monitored continuously on an oscilloscope (Finkel and Redman, 1985). Current and voltage records were filtered at $0.3 \mathrm{kHz}$ and usually acquired by D/A sampling and acquisition software (pCLAMP, Axon Instruments). For $I_{\mathrm{M}}$ studies, we most often applied $-5,-10,-15$, and $-20 \mathrm{mV}$ voltage commands in sequence three to five times for subsequent averaging. Current measures thus were derived from averages of three to five sweeps at each of the four voltage commands.

The various problems (e.g., space clamping) associated with voltage clamping of neurons with extended processes are discussed elsewhere (Halliwell and Adams, 1982; Johnston and Brown, 1983; Finkel and Redman, 1985). These problems may be less acute when dealing with relative changes following drug application (see Madison et al., 1987). Notwithstanding, we repeated some studies with SS in the presence of various pharmacological agents, to minimize the contribution of large non- $\mathrm{K}^{+}$conductances (e.g., $\mathrm{Na}^{+}$and $\mathrm{Ca}^{2+}$ ) in remote dendrites (see 
below). In some cells, we used whole-cell recording in a "blind" patchslice configuration (Blanton et al., 1989) with the membrane potential held throughout at -60 to $-70 \mathrm{mV}$ except for short command steps.

$M$-current analysis. In hippocampal CAl pyramidal neurons, $I_{M}$ is best seen with holding potentials of -40 to $-45 \mathrm{mV}$ and hyperpolarizing command steps of 5-25 mV and durations of 700-1000 msec (Halliwell and Adams, 1982). Here $I_{\mathrm{M}}$ appears as a slow inward current "relaxation" following the instantaneous (ohmic) inward current drop (Fig. $2 A$ ). As the instantaneous current jump at command onset is larger than that at command offset, the relaxation represents the inactivation of an outward $\left(\mathrm{K}^{+}\right)$current rather than the activation of an inward current. $I_{\mathrm{M}}$ amplitude was measured with software (CLAMPFIT, Axon Instruments) that fitted exponential curves (one exponent, $r$ valucs $=0.95-0.99$ ) to the $I_{M}$ relaxation. We used the difference between the instantaneous peak current at command onset and the steady-state current just before command offset to quantify the magnitude of $I_{\mathrm{M}}$ (see Fig. 2). Tail (offcommand) currents were not analyzed because of possible contamination with other currents. Usually, a current (capacitative) artifact of 5$20 \mathrm{msec}$ duration was present at command onset (see also Halliwell and Adams, 1982). Therefore, for estimation of the instantaneous portion of $I_{\mathrm{M}}$ with hyperpolarizing commands, the current relaxation was fitted via two methods: (1) curve fitting to the peak of the initial (quasiinstantaneous) current (Fig. 2Aa) that usually fell within 5-20 msec of step onset after complete settling of the capacity transient, or (2) exponential fitting through the peak with extrapolation to command onset (Fig. $2 \mathrm{Ab}$ ), based on the finite duration of the initial capacitative artifact and the exponential (monotonic) nature of the $I_{\mathrm{M}}$ relaxation. These methods gave essentially equivalent results with respect to relative effects of drugs, although the extrapolated $I_{\mathrm{M}}$ amplitude was obviously bigger $(10-25 \%$; average $20 \%$ ) than amplitude at peak (Fig. $2 B$ ). For statistical purposes the first method was used.

$Q$-current analysis. The Q-current $\left(I_{\mathrm{Q}}\right)$ is an anomalous or inward rectifier current carried by $\mathrm{Na}^{+}$and $\mathrm{K}^{+}$and seen in hippocampal pyramidal neurons (Halliwell and Adams, 1982). Like $I_{\mathrm{M}}$, it produces a slow inward current relaxation with hyperpolarizing voltage steps, although only from hyperpolarized holding potentials (more negative than $-65 \mathrm{mV}$ ) and via activation of an inward current. The amplitude of the relaxation increases as a function of the command hyperpolarization. $I_{0}$ and other forms of anomalous rectification were pharmacologically distinguished from $I_{\mathrm{M}}$ by their differential sensitivity to extracellular cesium $\left(2 \mathrm{~mm}\right.$; to block $I_{\mathrm{Q}}$ ) or the muscarinic agonist carbachol $(\mathrm{CCh}$; $25 \mu \mathrm{M}$; to block $I_{\mathrm{M}}$ ).

Large inward conductances and whole-cell patch clamp. In studies designed to minimize the possibility that the current relaxations measured were artifacts of large, non- $\mathrm{K}^{+}$conductance changes (e.g., remotely in the dendrites), we injected a local anesthetic, $\mathrm{Na}^{+}$channel blocker QX-314 (25-100 $\mathrm{mm}$ in the recording pipette), while superfusing TTX $(0.5-1 \mu \mathrm{M})$ and $\mathrm{CdCl}_{2}(50-300 \mu \mathrm{M})$ to block $\mathrm{Na}^{+}$and $\mathrm{Ca}^{2+}$ currents. We verified the action of these agents in current-clamp mode by following the loss of current-evoked $\mathrm{Na}^{+}$- and $\mathrm{Ca}^{2+}$-dependent action potentials.

To assess the effect of SS on $\mathrm{Ca}^{2+}$ currents in CA1 pyramidal neurons, we used whole-cell voltage clamp ("blind patch slice"; see Blanton et al., 1989) in continuous mode. The whole-cell patch pipette usually contained (in mM) Cs-gluconate, 130; HEPES, 10; $\mathrm{MgCl}_{2}, 2 ; \mathrm{Mg}_{2}$ ATP, 2; $\mathrm{Na}_{2} \mathrm{GTP}, 1$; tetraethylammonium (TEA), 2; BAPTA, 0.6; and leupeptin, 0.1. Pipette tip resistance was 3-5 M 2 . To elicit high-threshold $\mathrm{Ca}^{2+}$ currents in the whole-cell configuration, we held the cells at around $-60 \mathrm{mV}$ and applied voltage steps from -52 to $+12 \mathrm{mV}$ (usually at $+8 \mathrm{mV}$ increments). TEA at $20 \mathrm{mM}$ and TTX at $0.75-1 \mu \mathrm{M}$ were added to the extracellular ACSF to block $\mathrm{K}^{+}$channels and sodium spikes.

Drug administration. Drugs and peptides were made from a stock solution and added to the ACSF in known concentrations immediately before administration to the slice chamber. The usual drug protocol followed for agonist testing was to record currents during superfusion of ACSF alone ("control"), followed by switching of ACSF with drug and repeating these current measures after 5-10 min of drug, then followed by switching again to ACSF alone for 15-30 min with subsequent current measures ("washout"). The cell was depolarized to about -45 $\mathrm{mV}$ for $I_{M}$ analysis at each of these three periods, but was held near resting potential between these periods to avoid the instabilities that occasionally develop with prolonged depolarization (see Halliwell and Adams, 1982). For tests of the enzyme inhibitors, because AA and SS did not affect all neurons (roughly $70 \%$ ), the usual protocol involved first applying the agonist (AA or SS, with measurements as above), and then quickly adding the inhibitor to the agonist superfusate once a positive agonist response was established. This protocol was feasible because, once initiated, the $I_{\mathrm{M}}$ effect of SS or AA did not show desensitization over the complete testing period. In some cells, the antagonist was superfused alone to test possible effects on baseline properties. In a few other cells, the inhibitor was applied first (for 6-7 min), followed by addition of the agonist.

Somatostatin was obtained from Drs. J. Rivier and W. Vale at the Salk Institute and M. Buchmeier at The Scripps Research Institute. Arachidonic acid (AA; Sigma), hydroperoxy acids (Cayman Chemical), leukotrienes (Sigma), 5-LOX inhibitors (Biomol), and prostaglandins (Sigma) were stored at $-80^{\circ} \mathrm{C}$ and used immediately after suspension; the lipids were dried under nitrogen and dissolved in the ACSF by sonication. Prcparations of lipids showing prccipitate or droplets after sonication (indicating lack of solution in the ACSF) were discarded. We dissolved nordihydroguaiaretic acid (NDGA; Sigma), 4-bromophenacyl bromide (4BPB; Sigma), baicalein (Biomol), and leukotrienes in $0.1 \%$ dimethyl sulfoxide (DMSO), and AA in $0.25 \%$ DMSO. DMSO alone in the superfusion medium at the concentration used during our experiments had no significant effect on seven cells. However, we observed a small decrease in $I_{\mathrm{M}}$ and a small inward current slowly developing when testing $0.5 \%$ DMSO. Quinacrine (mepacrine, Sigma) was dissolved directly in the ACSF. Indomethacin (Sigma) was dissolved in ACSF containing $16 \mathrm{~mm}$ ethanol, which alone did not affect $I_{M}$ (see Moore et al., 1990). 8-Bromo-cAMP (8-Br-cAMP), dibutyryl-cAMP, and carbachol (CCh) were obtained from Sigma; QX-314 was a gift of Astra Pharmaceuticals.

\section{Results}

We studied a total of $145 \mathrm{CA} 1$ pyramidal neurons. These neurons had an average resting membrane potential (RMP) of -66.7 $\pm 0.5 \mathrm{mV}$ (mean $\pm \mathrm{SEM}$ ) and action potential amplitude of $102 \pm 0.6 \mathrm{mV}(n=87)$; mean resistance was $56 \mathrm{M} \Omega(n=72)$ at RMP. Stable recordings could be maintained for up to $4 \mathrm{hr}$, suggesting a relative lack of injury by the electrode penetration. We tested $I_{\mathrm{M}}$ using voltage clamp at holding potentials of -38 to $-50 \mathrm{mV}$ (mean, $-42.7 \pm 0.4 \mathrm{mV}$ ). The mean (outward) holding current reached at these depolarized potentials was 635 $\pm 31 \mathrm{pA}$. The $I_{\mathrm{M}}$ relaxation was voltage dependent with a maximum amplitude of 70-150 pA (103 $\pm 4 \mathrm{pA})$ in control condition, using commands of -5 to $-20 \mathrm{mV}$. Several lines of evidence suggest, as reported previously (Halliwell and Adams, 1982; Moore et al., 1988), that the relaxations represent $I_{\mathrm{M}}:(1)$ the relaxations are suppressed (leaving only a "rectangular" ohmic current response) by the muscarinic agonists $\mathrm{CCh}$ or muscarine $(10-40 \mu \mathrm{M})$ or by $1 \mathrm{~mm} \mathrm{Ba}{ }^{2+}$, (2) the current-voltage curves for the relaxations are shifted in a positive direction by an increase of $\mathrm{K}^{+}$in the medium, (3) the magnitude, kinetics, and voltage dependence of the relaxations appear equivalent to those of the pyramidal cell M-current reported previously.

\section{SS effects on $\mathrm{I}_{M}$ and $\mathrm{I}_{Q}$}

In accord with our previous reports (Moore et al., 1988; Schweitzer et al., 1990), superfusion of SS ( $1 \mu \mathrm{M})$ elicited in CA1 hippocampal pyramidal neurons an outward current with a concomitant increase in $I_{\mathrm{M}}$ amplitude and input conductance (Fig. 3). The current recording (Fig. $3 A$ ) exhibits a slow inward deflection (relaxation) at the onset of each hyperpolarizing step. These relaxations are due to the inactivation of the $I_{\mathrm{M}}$ for the steps positive to $-70 \mathrm{mV}$, and activation of $I_{\mathrm{Q}}$ for the hyperpolarizing steps more negative than $-70 \mathrm{mV}$. Superfusion of SS elicits an outward current in the depolarized range with no effect at more hyperpolarized potentials. A plot of the steadystate current versus voltage (Fig. $3 B$ ) reveals the outward rectifying nature of $I_{\mathrm{M}}$ in the -40 to $-70 \mathrm{mV}$ range and the inward rectifying behavior of $I_{\mathrm{Q}}$ in the -70 to $-95 \mathrm{mV}$ range. Measurements of the relaxation amplitudes show that SS increases 
Figure 2. $I_{\mathrm{M}}$ protocol and relaxation fitting. $A$, Current recording of a $\mathrm{CAl}$ pyramidal neuron clamped at $-43 \mathrm{mV}$ and submitted to a $5 \mathrm{mV}$ hyperpolarizing step. The slow inward (downward) relaxation reflects the reduction of the noninactivating time- and voltage-dependent $\mathrm{M}$-current $\left(I_{\mathrm{M}}\right)$, carried by the outward flow of $\mathrm{K}^{+}$. $I_{\mathrm{M}}$ relaxation amplitude is estimated from the peak of the relaxation (Iinst, instantaneous current) to the end of the voltage step where a steady baseline current is reached (Istst, steady-state current). We estimated the $I_{\mathrm{M}}$ relaxation amplitude by two methods (see Materials and Methods): $a$ shows fitting to peak (with magnification of the current trace shown in the broken circle in $A$ ); $b$, fitting with extrapolation back to command onset. $B$, Graph of $I_{\mathrm{M}}$ amplitude (average of 39 cells) plotted against hyperpolarizing step command $(5,10,15$, and $20 \mathrm{mV}$; holding potential, $-43 \mathrm{mV}$ ). $a$, M-current fitting to the peak of the relaxation; $b, I_{\mathrm{M}}$ fitting with extrapolation to command onset. Observe the similarity of shape of the peak and extrapolated graphs and the $I_{\mathrm{M}}$ increase by SS, except that $I_{\mathrm{M}}$ amplitudes are $17 \%$ larger when extrapolating the fit to command onset (note the different $y$-axis scales in $a$ and b).

A

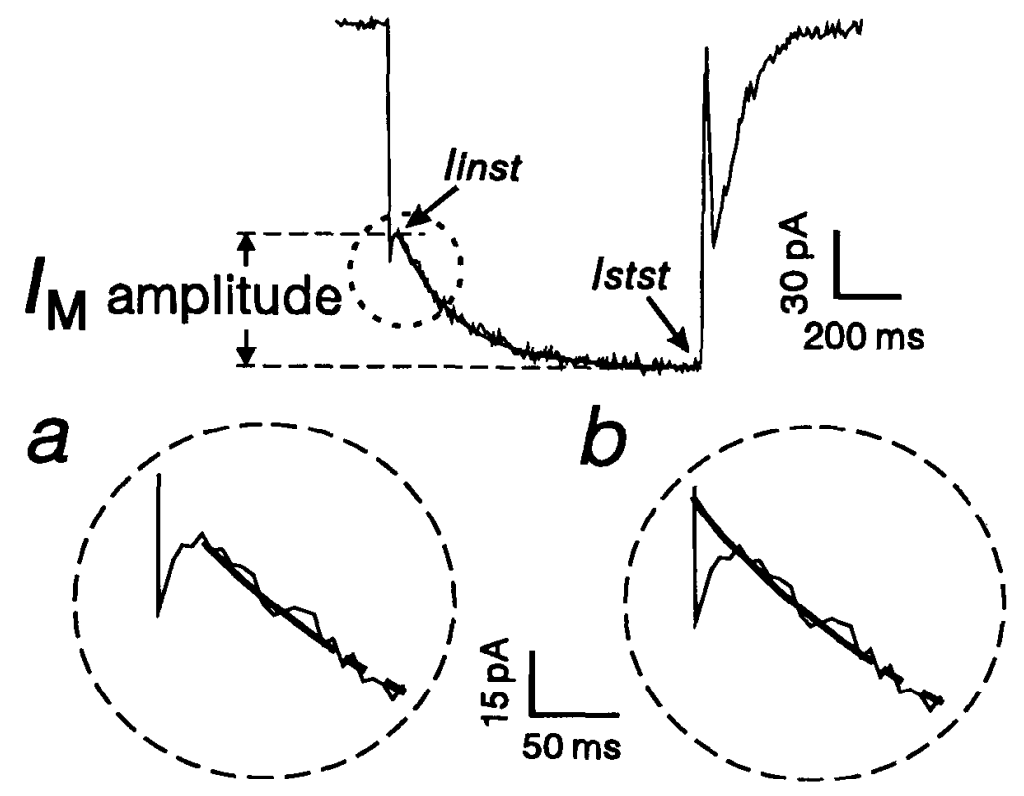

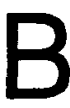

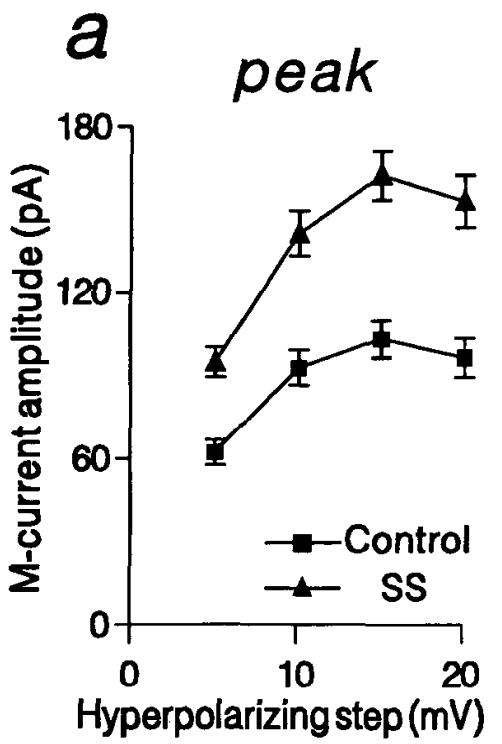

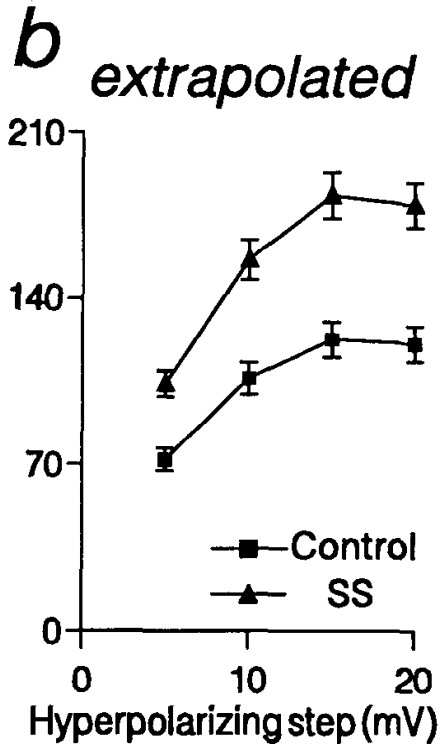

$I_{\mathrm{M}}$ without affecting $I_{\mathrm{Q}}$ (Fig. $3 C$ ), as seen in most neurons (although three cells showed an increase in the $I_{\mathrm{Q}}$ relaxation).

Of 53 cells tested with SS, 39 responded with an increased $I_{\mathrm{M}}$ amplitude of 55-60\% across all voltage commands (Fig. $4 A$ ). This was associated with an outward (steady-state) current shift relative to control (Fig. $4 B)$ at both resting $(61 \pm 8 \mathrm{pA})$ and depolarized potentials $(221 \pm 20 \mathrm{pA}$ at $-43 \mathrm{mV})$. These effects usually occurred within 1-3 min after SS reached the inner slice chamber, with peak responses occurring at 4-6 min. Recovery to control measures usually required about $15 \mathrm{~min}$ of SS washout with ACSF alone. Among the 14 neurons that did not show an $I_{\mathrm{M}}$ augmentation with $\mathrm{SS}, 8$ revealed a small outward current in the presence of SS (40-80 pA from -70 to $-40 \mathrm{mV}$ holding potentials).

\section{SS effects on depolarization-evoked inward currents}

We examined the possibility that large inward conductances such as $\mathrm{Na}^{+}$or $\mathrm{Ca}^{2+}$ might be involved in the SS effects, by treating the $\mathrm{CA} 1$ neurons with agents that block these currents. Injection or leakage of QX-314, the local anesthetic $\mathrm{Na}^{+}$channel blocker (Connors and Prince, 1982), into the cells from pipettes containing high concentrations (50-100 $\mathrm{mm}$ ) of the drug often appeared to lead to smaller M-current relaxations, suggesting nonspecific actions on $\mathrm{K}^{+}$channels. Use of pipettes containing a $25 \mathrm{~mm}$ concentration of the agent had no obvious effect on $I_{\mathrm{M}}$ or other $\mathrm{K}^{+}$conductances such as those underlying the postburst afterhyperpolarizations (AHPs), but $\mathrm{Na}^{+}$-dependent spikes recorded in current-clamp mode were blocked within 10-15 min 
A

Control
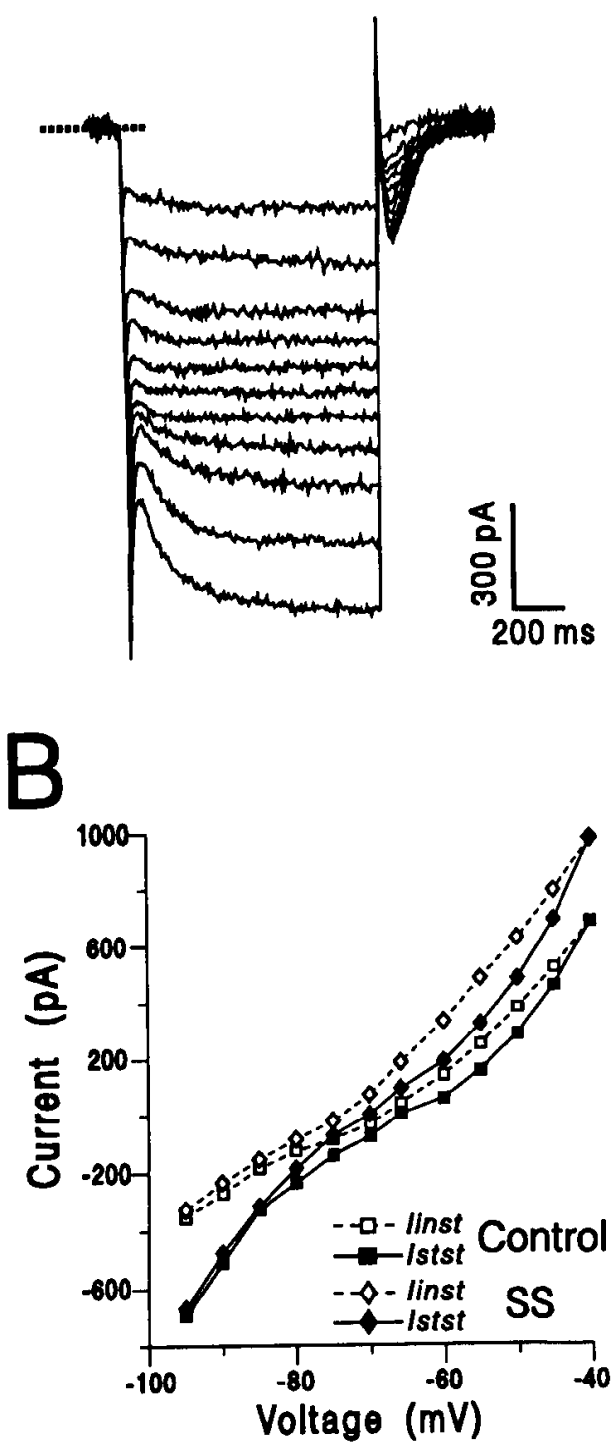

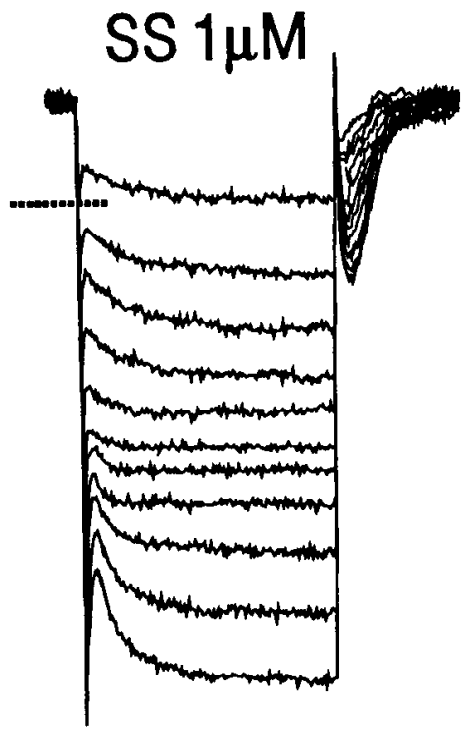

C

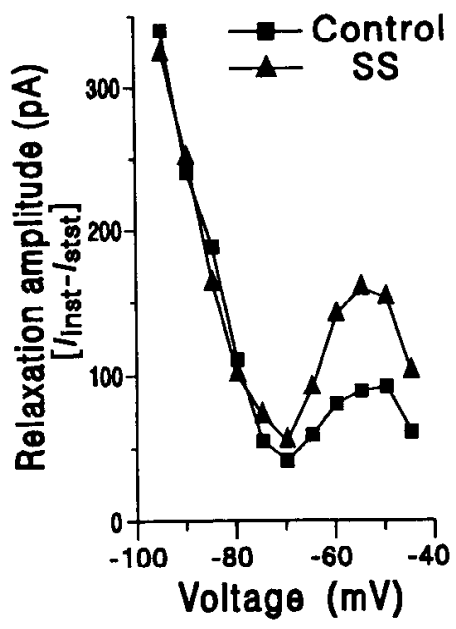

Figure 3. Effect of SS on current-voltage relationships of a $\mathrm{CA} 1$ pyramidal neuron. $A$, Superimposed current recording of a neuron held at $-40 \mathrm{mV}$ and hyperpolarized, by $-5 \mathrm{mV}$ incrementally increasing steps, to $-95 \mathrm{mV}$. RMP was $-66 \mathrm{mV}$ for this cell. The current relaxation seen from -45 to $-70 \mathrm{mV}$ is due to $I_{\mathrm{M}}$; note the outward steady-state current in the depolarized range (broken line, control holding current) and the $I_{M}$ increase observed in the presence of SS (6 min after onset). The relaxation appearing between -75 and $-95 \mathrm{mV}$ is due to the anomalous (inward) rectifier or Q-current. $B$, Plots of instantaneous current (Iinst; see Fig. $2 A$ ) and steady-state current (Istst) before (control) and during $1 \mu \mathrm{M}$ SS superfusion, taken from data in $A$. Note convergence of the linst and Istst curves between -70 to $-80 \mathrm{mV}$, indicating lack of SS effect in the hyperpolarized range. $C$, Curve of voltage dependence of rclaxation amplitude (Iinst minus Istst) measured as in Figure $2 A$ shows $I_{\mathrm{M}}$ and $I_{\mathrm{Q}}$ amplitudes, with overlap of the curves from about $-75 \mathrm{mV}$ to -95 $\mathrm{mV}$ showing that $I_{\mathrm{Q}}$ is not affected by SS. By contrast, SS elicits separation of the curves from $-70 \mathrm{mV}$ into the depolarized $\left(I_{\mathrm{M}}\right)$ range. of cell penetration. At this point, increasing the strength of dcpolarizing current steps evoked broad, slowly developing spikes typical of $\mathrm{Ca}^{2+}$-dependent action potentials (Fig. $5 \mathrm{~A}$ ). As these spikes were always completely blocked by subsequent super-

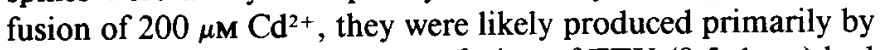
$\mathrm{Ca}^{2+}$ currents. Subsequent superfusion of TTX $(0.5-1 \mu \mathrm{M})$ had little or not effect on the shape of these spikes.

SS ( $\mu \mathrm{M})$ superfusion, whether with or without TTX, had little or no effect on the shape or size of the $\mathrm{Ca}^{2+}$-dependent spikes (Fig. $5 A$ ) in seven of eight neurons (five recorded with pipettes containing $25 \mathrm{~mm}$ QX-314, two with $50 \mathrm{~mm}$, one with $80 \mathrm{~mm}$ ). Only one neuron showed a small reversible decrease in the $\mathrm{Ca}^{2+}$-dependent spike. In patch-clamp studies, neurons recorded in the whole-cell configuration using pipettes containing $\mathrm{Cs}^{+}$and TEA to block $\mathrm{K}^{+}$channels, and with TEA in the superfusate, showed pronounced inward currents on depolarization from holding potentials of $-60 \mathrm{mV}$ with command steps from -44 to $+12 \mathrm{mV}$. These currents are likely to be carried by $\mathrm{Ca}^{2+}$, because they are activated at around $-35 \mathrm{mV}$, show current-voltage characteristics typical of the high-threshold $\mathrm{Ca}^{2+}$ current (see Fig. 5B), and are blocked by $\mathrm{Cd}^{2+}$ at 50-200 $\mu \mathrm{M}$. Superfusion of SS at $1 \mu \mathrm{M}$ had little consistent effect on the amplitude of the inward currents in four of six cells (Fig. 5B). In the two other cells an apparent small reduction of the currents by SS could not be reversed by washout with ACSF alone; rather, the inward currents continued to get smaller, suggesting a "rundown" effect probably due to the whole-cell recording configuration.

To examine further the possibility that large remote $\mathrm{Na}^{+}$and or $\mathrm{Ca}^{2+}$ conductances contribute to the SS effects, in eight cells QX-314 (25-100 $\mathrm{mm}$ in the pipette) was injected intracellularly and TTX and $\mathrm{Cd}^{2+}(200 \mu \mathrm{M})$ applied extracellularly during recording of $I_{\mathrm{M}}$ relaxations. Under these pharmacological conditions, the $I_{M}$ relaxations were generally smaller than in TTX alone (especially with higher QX-314 concentrations) and often slowly decreased over time (about $1 \mathrm{hr}$ ), probably as a result of 

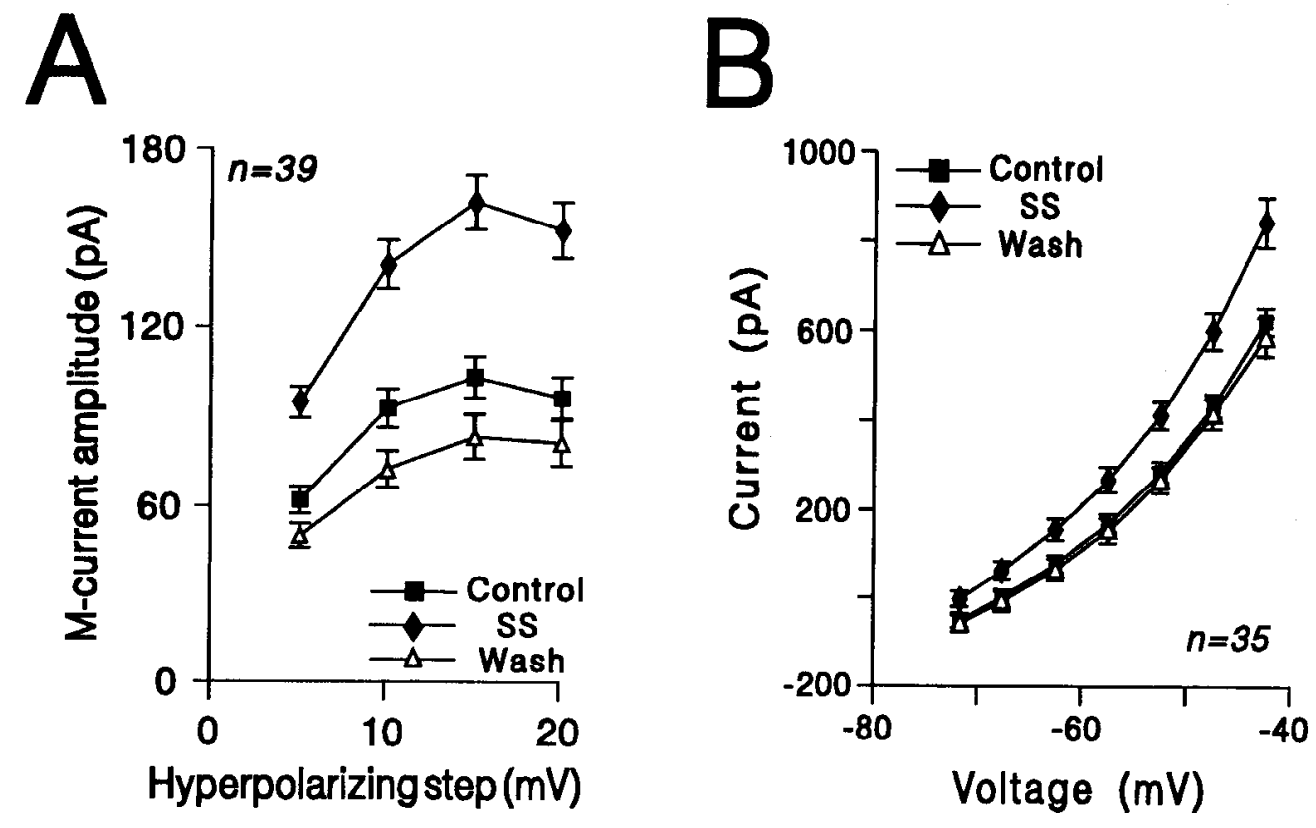

Figure 4. SS effects averaged across $39 \mathrm{CA} 1$ pyramidal neurons. $A$, SS increases the mean ( \pm SEM) $I_{\mathrm{M}}$ relaxation amplitudes averaged from 39 cells, by $55-60 \%$ (from 104 to $163 \mathrm{pA}$ for the maximum amplitude reached). Mean holding potential was $-43 \mathrm{mV} . R$, Average current-voltage relationship of 35 CAl pyramidal neurons. SS elicits a mean outward steady-state current that increases on depolarization, with recovery on washout. Error bars in this and all subsequent figures represent \pm SEM values.

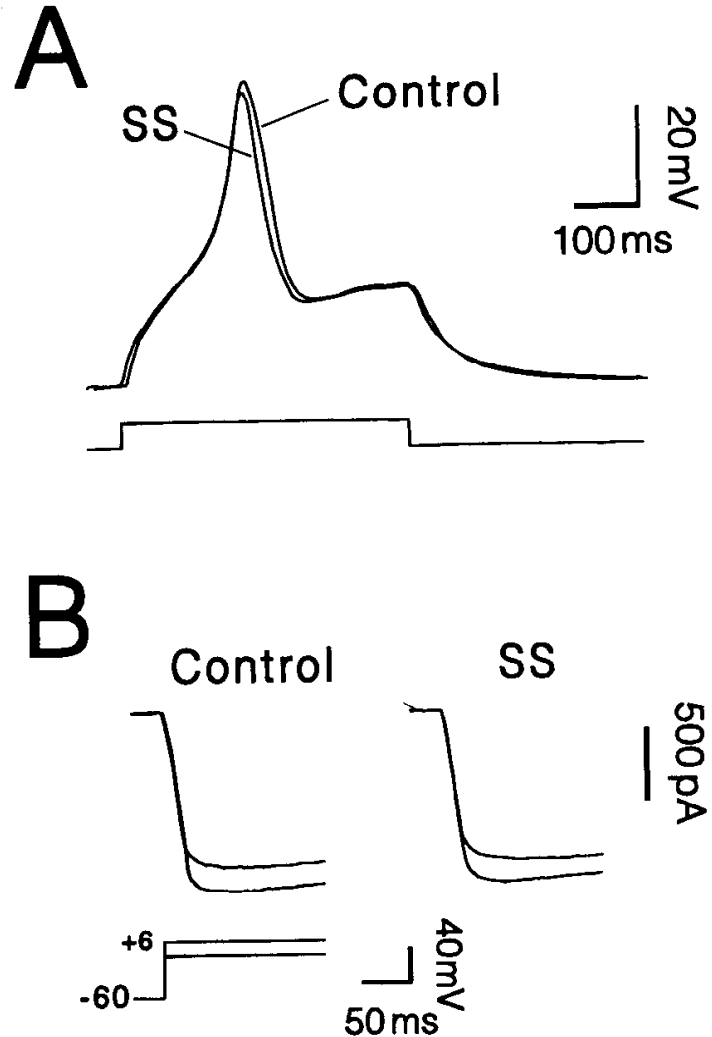

Figure 5. SS has little effect on calcium-dependent action potentials or high-threshold $\mathrm{Ca}^{2+}$ currents. $A$, Superimposed voltage traces of CA1 neuronal responses to depolarizing current injection in current-clamp mode, recorded with a sharp pipette containing QX-314 (25 mM) and with TTX $1 \mu \mathrm{M}$ in the bathing medium. Superfusion of $1 \mu \mathrm{M} \mathrm{SS}$ resulted in a very slight decrease in the amplitude of the $\mathrm{Ca}^{2+}$-dependent action potential that never recovered with washout. RMP was $-68 \mathrm{mV} . B$, Different CAl pyramidal neuron recorded in the whole-cell, voltageclamp configuration. The patch pipette contained $130 \mathrm{~mm}$ Cs-gluconate and $2 \mathrm{~mm}$ TEA to block $\mathrm{K}^{+}$channels; the superfusion medium also contained TEA at $20 \mathrm{mM}$, and $1 \mu \mathrm{M}$ TTX to block Na ${ }^{+}$channels. Selected inward currents resulting from two (to $-12 \mathrm{mV}$ and $+6 \mathrm{mV}$; voltage protocol on lower left) of several (not shown) depolarizing steps from a $-60 \mathrm{mV}$ holding potential, subtracted for leak currents. SS superfusion $(1 \mu \mathrm{M})$ had no significant cffcct on the inward currents. RMP $=-47$ $\mathrm{mV}$ (depolarized due to intracellular $\mathrm{Cs}^{+}$). nonspecific actions of QX-314 or $\mathrm{Cd}^{2+}$. Nonetheless, in seven cells with a measurable $I_{M}$ relaxation (25-50 mM QX-314 in the pipette), SS $(1 \mu \mathrm{M})$ superfusion increased the $I_{\mathrm{M}}$ relaxations in four cells by $25-250 \%$ (mean: $105 \%$ ). The other three cells either showed no change of $I_{M}$ with SS superfusion or exhibited a slow $I_{M}$ "rundown" over timc.

\section{$C A M P$}

To examine a possible mediator role of cAMP in the SS- $I_{M}$ effect, we tested 8-Br-cAMP (0.5-2.5 mM) on six cells. On average, 8-Br-cAMP evoked an early (1-2 min), small (25 pA) outward current, which reversed to a small inward current $(-35$ pA) after 3-4 min of superfusion. These effects were associated with decreased conductance $(8-10 \%)$ and a slight $(10 \%)$ reduction in $I_{\mathrm{M}}$. One cell showed a small $I_{\mathrm{M}}$ increase $(20 \%)$ associated with little outward steady-state current. Dibutyryl-cAMP (1 mM) was tested in two cells. One responded with an $I_{M}$ increase (20\%) and an outward steady-state current $(70 \mathrm{pA})$ at depolarized potentials, with recovery on washout. The other cell did not show a measurable response.

\section{Involvement of $P L A_{2}$ in SS effects}

To test the involvement of the PLA $\mathrm{P}_{2}$ system (Fig. 1) in the SS effects, we superfused two substances that can inhibit PLA (see Fig. 1 caption for drug references), 4BPB (10 $\mu \mathrm{M}$; seven cells) and quinacrine ( $8 \mu \mathrm{M}$; eight cells). Both abolished all SS effects: the augmentation of $I_{M}$ (Fig. $6 A$ ) and the outward current shift (Fig. $6 B$ ) returned to near control levels. To identify the current effects of these compounds, we subtracted the current-voltage relationship obtained during drug application from that obtained in the control condition. Thus, Figure $6 C$ shows the net outward current elicited by SS, which is fully abolished in the presence of $4 \mathrm{BPB}$. The difference between these two currents is the 4BPB-sensitive component. 4BPB, like quinacrine (data not shown), completely blocked SS-induced effects. Neither 4BPB (four cells) nor quinacrine (four cells) alone in the superfusion medium had a measurable effect on control $I_{\mathrm{M}}$ or steady-state current (data not shown).

We also tested mellitin $(1-5 \mu \mathrm{g} / \mathrm{ml})$, an activator of PLA 
A

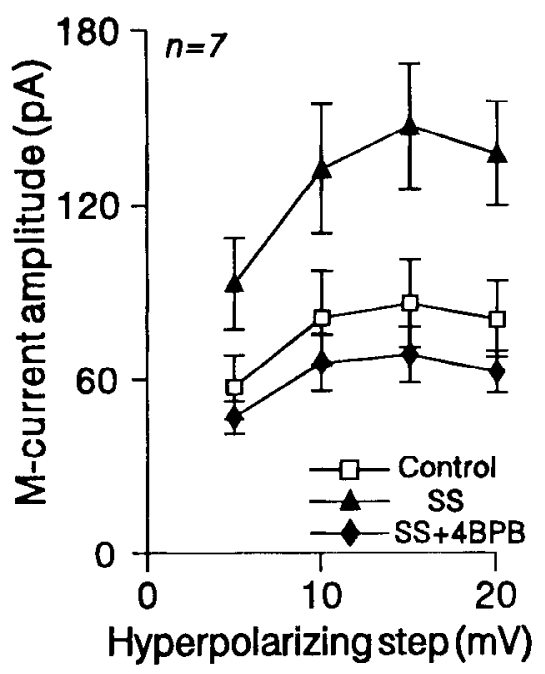

B

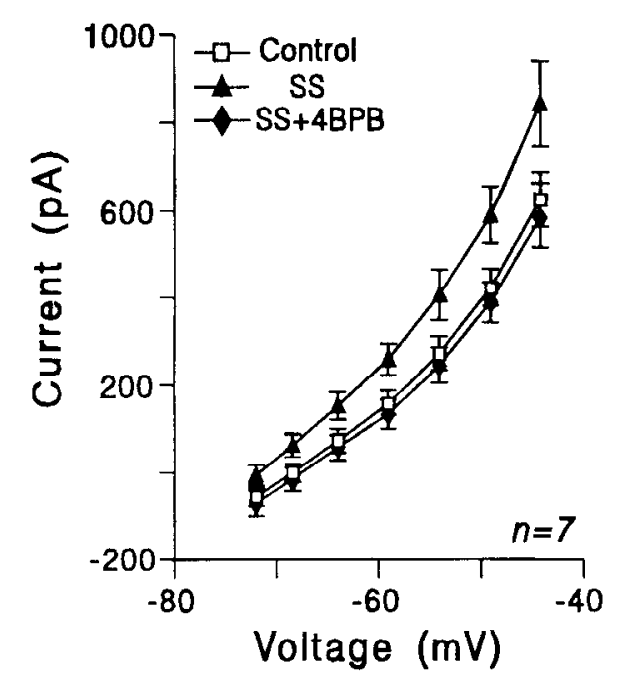

C

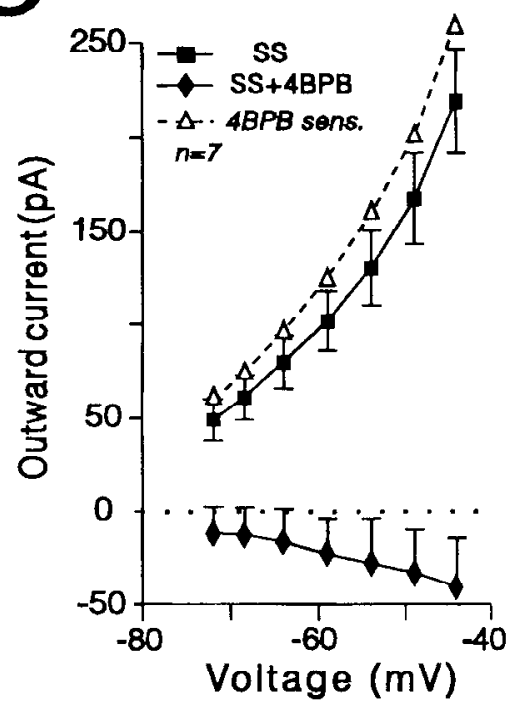

Figure 6. SS effects are blocked by the PI $\mathrm{A}_{2}$ inhihitor $4 \mathrm{BPB} . A$, Mean $I_{\mathrm{M}}$ amplitude is increased by SS, and this effect is completely abolished by application of $4 \mathrm{BPB}$ together with SS. $B$, Current-voltage curve showing that the SS-induced outward steady-state current is also completely reversed by concomitant superfusion of $4 \mathrm{BPB}$. $C$, Graph of net SS induced current before and during 4BPB; data were obtained from $B$ by subtracting the control from the SS and SS+4BPB currents. Unlike NDGA (see Fig. 11A), 4BPB reverses all SS effects, as indicated by the 4BPB-sensitive curve (4BPB sens., broken curve).

(Shier, 1979), on four cells. In one cell mellitin increased $I_{\mathrm{M}}$ by $23 \%$ with a $10 \%$ increase in input conductance; in the three other cells, only a slight outward current could be detected (about $30 \mathrm{pA}$ ). In all cases, these effects were short-lived (a few minutes) and followed by an inward current without recovery that was associated with either a conductance increase (two cells), decrease (one cell) or no change (one cell).

\section{AA mimics SS}

Inhibition of SS effects by phospholipase inhibitors led us to examine the effects of AA, the initial product of the PLA $\mathrm{A}_{2}$ pathway (see Fig. 1). Figure $7 A$ shows the current records of a $C A 1$ neuron superfused with $\mathrm{AA}$. In this experiment we superfused ACSF containing $2 \mathrm{~mm} \mathrm{CsCl}$ to block $l_{\mathrm{Q}}$. Like SS, AA elicited $I_{\mathrm{M}}$ augmentation and an outward steady-state current in three of three neurons bathed with $2 \mathrm{~mm} \mathrm{Cs}$. With $I_{\mathrm{Q}}$ blocked, we were able to determine the $I_{\mathrm{M}}$ reversal potential (Fig. $7 B$ ), and estimate the M-conductance variation (Fig. $7 C$, caption). The $I_{\mathrm{M}}$ reversal potential was $-80 \mathrm{mV}$ for this cell, and the $\mathrm{M}$-conductance increased from $3.7 \mathrm{nS}$ in the control condition to $7 \mathrm{nS}$ in the presence of AA.

In 33 of 45 cells, AA elicited a $55-75 \%$ increase in $I_{\mathrm{M}}$ amplitude (Fig. $8 A$ ), and caused a net outward current at both resting potential $(66 \pm 10 \mathrm{pA})$ and at depolarized potentials $(233 \pm 16 \mathrm{pA}$ at $43 \mathrm{mV}$ ) (Fig. $8 B$ ). The time course for these AA effects (1-3 min for response onset; peak effect, 5-6 min; 12-15 min for recovery on washout) was equivalent to that for SS. To verify that the AA effect indeed involved $I_{\mathrm{M}}$, we added $\mathrm{CCh}$, a muscarinic agonist, in the presence of AA. As shown in Figure $8 C$, CCh $(25 \mu \mathrm{M})$ blocked $I_{\mathrm{M}}$ and the concomitant outward current produced by $\mathrm{AA}$, supporting the notion that M-channels are the source of the relaxation increase, as previously demonstrated for SS (Moore et al., 1988). Of the 12 neurons in which AA did not modify $I_{\mathrm{M}}$, six exhibited an AAinduced outward current (40-90 pA from -70 to $-40 \mathrm{mV}$ holding potentials). This current amplitude was equivalent to that induced by SS in neurons in which SS did not increase $I_{\mathrm{M}}$.

\section{$S S$ and $A A$ increase $M$-current time constant}

The lime constant $(\tau)$ of the $I_{\mathrm{M}}$ relaxation increased with superfusion of either SS or AA. This augmentation reached significance $(P<0.001$ for SS, $P<0.002$ for AA; Student's $t$ test $)$ when averaged across 32 SS- and 28 AA-responding cells (Fig. 9). Avcrage control $t$ values at $-53 \mathrm{mV}$ (during a $10 \mathrm{mV}$ hyperpolarizing step from $-43 \mathrm{mV}$ holding potential) were 173 $\pm 12 \mathrm{msec}$ (mean $\pm \mathrm{SEM}$ ) for the group subsequently tested with SS and $177 \pm 13 \mathrm{msec}$ for the AA group, diminishing with further hyperpolarization as previously described (Adams and Brown, 1982; Halliwell and Adams, 1982). Mean $\tau$ (at the same average membrane potential, $-53 \mathrm{mV}$ ) increased to $219 \pm 17$ Insec with superfusion of SS (a 20-27\% increase across all four voltage steps; mean, 24\%) and $218 \pm 18 \mathrm{msec}$ with AA (23$31 \%$ increase across the four voltage steps; mean, $27 \%$ ). The average $\tau$ returned to near control levels on washout. Interestingly, all drugs blocking $I_{\mathrm{M}}$ augmentation (PLA ${ }_{2}$ and LOX inhibitors: see sections on LOXs below) also abolished the $\tau$ increase.

\section{COX pathway}

$\Lambda$ major route for $\Lambda \Lambda$ metabolism is the COX pathway, leading to formation of prostaglandins and thromboxanes (Fig. 1). However, superfusion (5-8 min) of indomethacin $(8-10 \mu \mathrm{M})$, a COX inhibitor, did not significantly antagonize SS-induced ( 10 cells) or AA-induced (5 cells) $I_{\mathrm{M}}$ augmentation or outward steadystate current (data not shown). In fact, in some cells the SS (five cells) and AA effects (two cells) were clearly increased by indomethacin, including a more pronounced outward steady-state current. However, prolonged indomethacin superfusion (15 min) reduced SS effects in three cells but never reduced AA effects. Superfusion of indomethacin onto cells that did not present SS- 


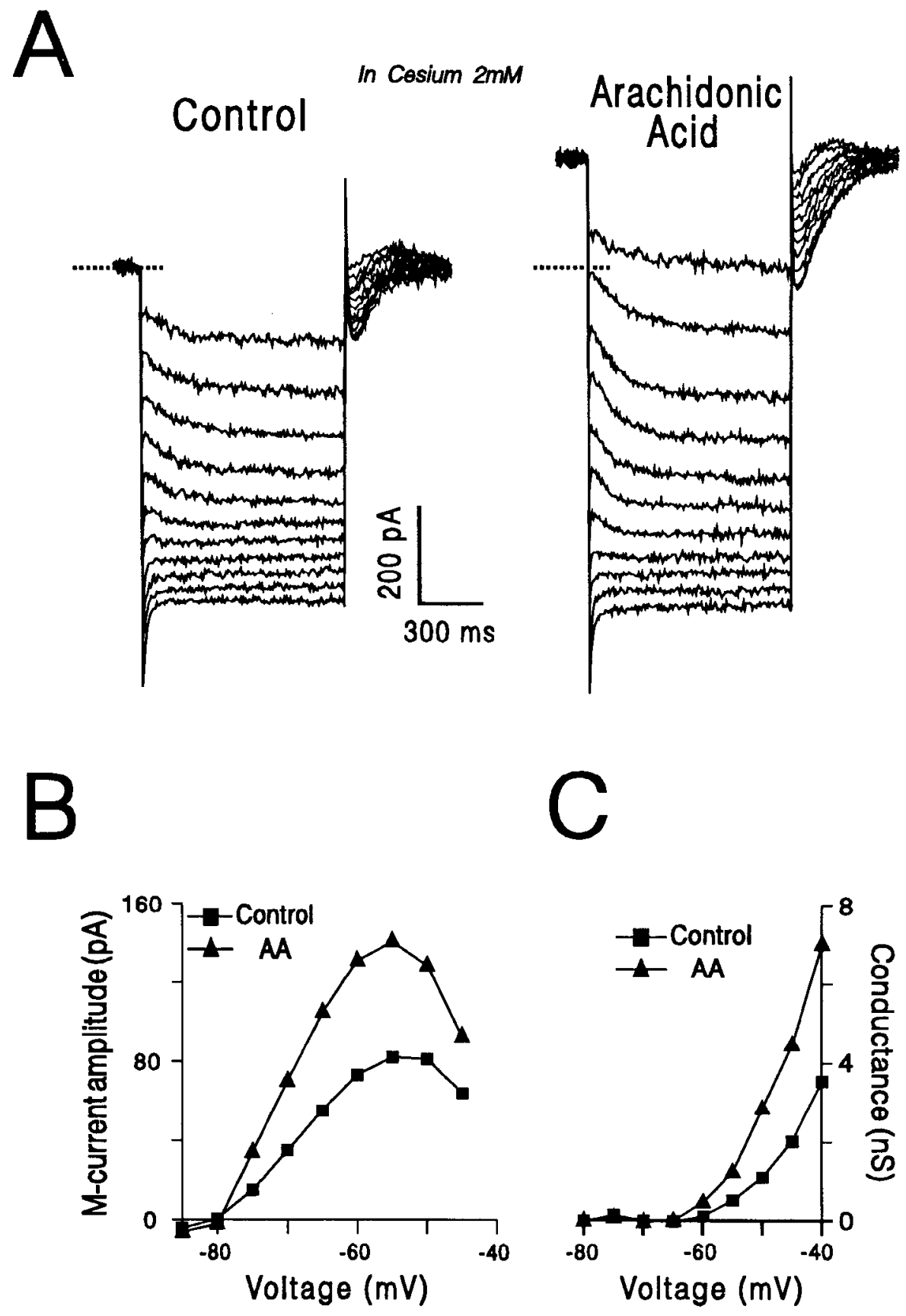

Figure 7. AA increases $I_{M}$ in a CAl pyramidal neuron. $A$, Current recording of a neuron held at $-40 \mathrm{mV}$ and hyperpolarized to $-95 \mathrm{mV}$ by $-5 \mathrm{mV}$ incrementally increasing steps. The superfusion medium contained 2 mм cesium to block $I_{0}$ (note the absence of relaxation at hyperpolarized potentials compared to Fig. 3A). Superfusion of AA $(130 \mu \mathrm{M})$ for $7 \mathrm{~min}$, like SS (see Fig. 3) elicits an outward steady-state current at the depolarized potentials, increases $I_{\mathrm{M}}$, and augments input conductance (larger currents are evoked by equivalent voltage steps). RMP was -68 $\mathrm{mV}$ for this cell. $B$, Same cell: plot of $I_{\mathrm{M}}$ amplitude versus voltage obtained from records in $A$. Note the large increase of $I_{\mathrm{M}}$ evoked by AA, with no change in the reversal potential $(-80$ $\mathrm{mV}) . C$, Data obtained from the same cell showing the changes in the M-conductance underlying the current relaxation (closing of M-channels), calculated by dividing the amplitude of relaxation (inverted across the range of voltage steps) by its driving force (holding potential minus reversal potential). This M-conductance is roughly doubled by AA. $(n=4)$ or AA- $(n=4)$ induced $I_{\mathrm{M}}$ augmentation did not cause any measurable effect (e.g., $I_{M}$ potentiation). Indomethacin alone had no effect on $I_{\mathrm{M}}$ relaxations or steady-state current (three cells).

We further investigated a possible involvement of the COX pathway by testing the prostanoids, prostaglandin $\mathrm{E}_{2}\left(\mathrm{PGE}_{2}\right)$, $\mathrm{PGF}_{2 \alpha}$, or $\mathrm{PGI}_{2} . \mathrm{PGE}_{2}(20-60 \mu \mathrm{M}$; three cells) had no effect on two cells and provoked a small inward current $(30 \mathrm{pA})$ in one cell with an input conductance decrease of $20 \%$ but no effect on $I_{\mathrm{M}}$. PGF $_{2 \alpha}$ (2-3 $\mu \mathrm{M}$; two cells) superfusion also caused a small depolarization in one cell with a $15 \%$ decrease in input conductance without affecting $I_{\mathrm{M}}$. There was no $\mathrm{PGF}_{2 \alpha}$ effect on the other cell. Both cells tested with $\mathrm{PGI}_{2}$ responded with some inward current at depolarized potentials; one exhibited a $35 \%$ decrease in $I_{\mathrm{M}}$. Thus, COX products did not consistently alter the CAl pyramidal neuron current-voltage relationships; rather, the effects observed involved a small inward current with no change in $I_{\mathrm{M}}$.

\section{OX pathways}

LOXs provide other routes for AA metabolism. Superfusion of NDGA $(10 \mu \mathrm{M})$, a general inhibitor of LOXs, had no significant effect when applied alone $(n=4)$. However, it abolished both the SS-induced ( 7 of 8 cells) and the AA-induced ( 11 of 11 cells) $I_{\mathrm{M}}$ augmentation (Fig. $10 \mathrm{~A}$ ), bringing $I_{\mathrm{M}}$ amplitudes back to control level. Nonetheless, NDGA superfusion did not completely reverse the overall SS- or AA-induced net outward current (Fig. 10B): a residual outward current remained with both SS and AA at the potentials tested. To separatc these different components, we subtracted the current-voltage curve during 


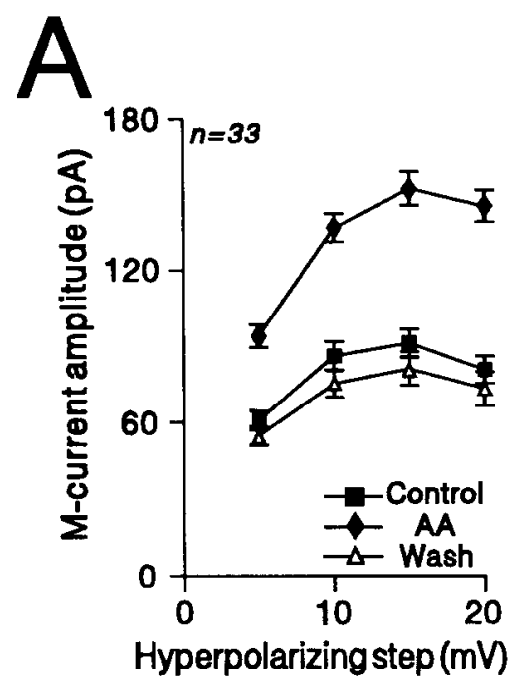

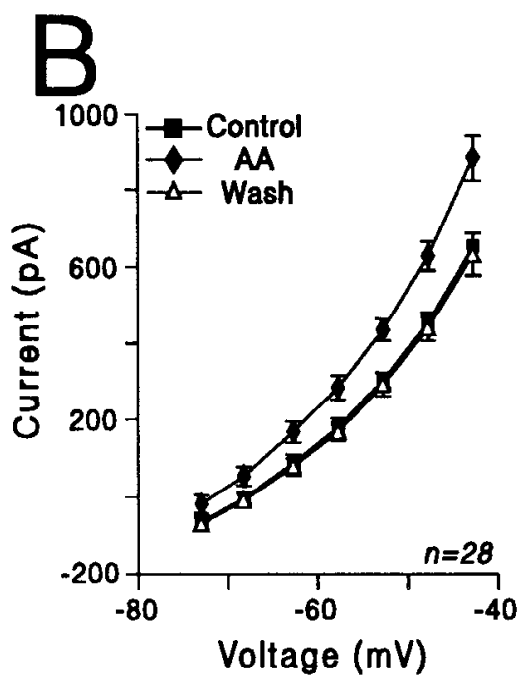

C AA $120 \mu \mathrm{M}$

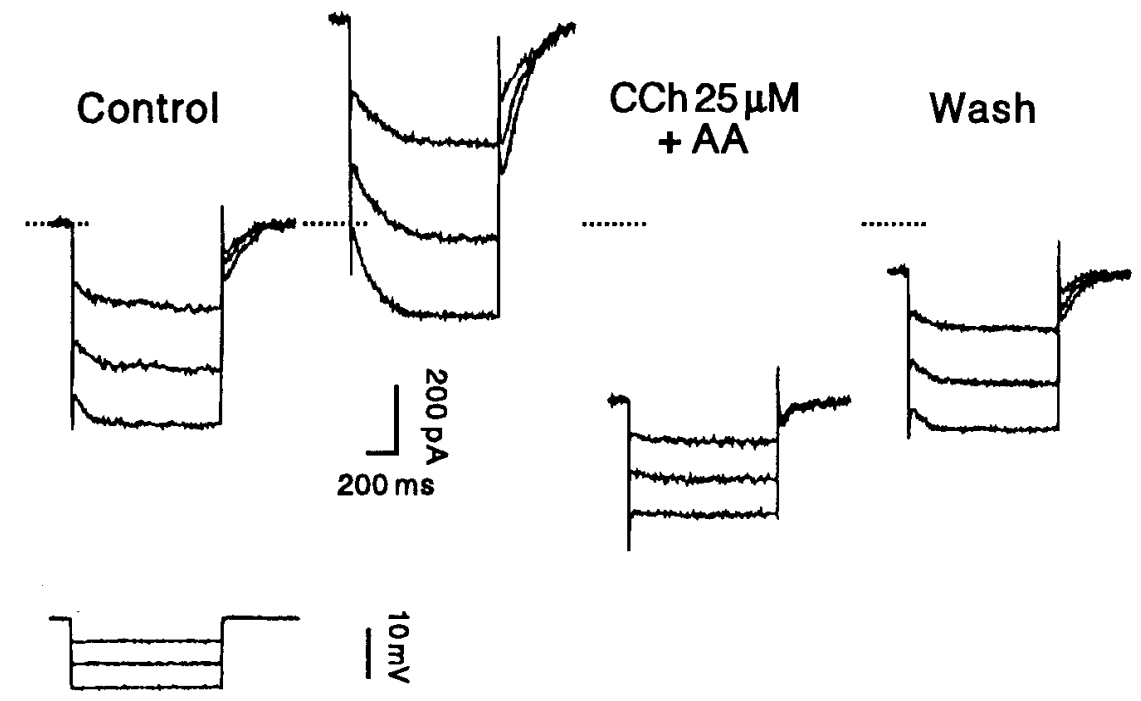

Figure 8. AA effects averaged across $33 \mathrm{CA} 1$ pyramidal neurons. $A$, AA increases mean $I_{\mathrm{M}}$ by $55-75 \%$ (from 91 to $152 \mathrm{pA}$ for the maximum amplitude reached). Mean holding potential was $-43 \mathrm{mV}$. $B$, AA elicits an outward steady-state current that increases with depolarization and is completely reversed after washout of the lipid. $C, I_{\mathrm{M}}$ relaxations, their increase by $\mathrm{AA}$, and the AA induced outward steady-state current (broken lines) are all completely blocked by $\mathrm{CCh}$, a muscarinic agonist. $\mathrm{CCh}$ also causes an additional steadystate inward current. These effects of $\mathrm{CCh}$ began within 1 min after the perfusate reached the slice chamber (peak effect within $2 \mathrm{~min}$ ); recovery to control levels required 15-20 min of washout with ACSF alone (see Pontzer et al., 1992). RMP was $-70 \mathrm{mV}$.
NDGA application from the control curve, as described for 4BPB. Figure $11 A$ shows the net outward currents elicited by SS (left panel) or AA (right panel) alone and in the presence of NDGA (contrast to Fig. $6 C$ ). The difference between these two currents reveals the component blocked by NDGA, that is, the $N D G A$-sensitive current (broken lines in Fig. $11 A$ ). Figure $11 B$ shows the conductance calculations relative to this NDGA-sensitive current: it activates at about $-65 \mathrm{mV}$, shows voltage dependency, and exhibits a net conductance augmentation of about $3.5-4 \mathrm{nS}$ around $-40 \mathrm{mV}$ (Fig. $11 \mathrm{~B}$ ); the extrapolated reversal potential is estimated to be $-82 \mathrm{mV}$ with $\mathrm{SS}$ and -83 $\mathrm{mV}$ with AA. Thus, addition of NDGA inhibits SS- or AAinduced $I_{\mathrm{M}}$ augmentation and much of the induced outward current (15-200 pA over the voltages tested), and reveals a residual SS- or AA-induced outward current of about $30-50 \mathrm{pA}$ remaining over the same range of potentials.

We also tested NDGA on those few neurons in which superfusion of SS or AA did not increase $I_{\mathrm{M}}$ but still induced a small outward current. In these cells, NDGA did not antagonize the $\mathrm{SS}(n=3)$ or AA $(n=2)$ effects.

\section{2- $L O X$}

Because 12-LOX-like immunoreactivity recently has been shown to exist in canine hippocampus (Nishiyama et al., 1992), we tested the effect of the specific 12-LOX inhibitor baicalein (4 $\mu \mathrm{M})$ on SS responses. Baicalein affected neither the SS-induced outward steady-state current nor the $I_{\mathrm{M}}$ increase in the five pyramidal neurons tested (Fig. 12). We also tested the primary metabolite of the 12-LOX pathway, 12-hydroperoxyeicosatetraenoic acid (12-HPETE). In five cells examined, two exhibited an outward current but without change in $I_{\mathrm{M}}$ amplitude. The three remaining cells did not exhibit any measurable effect.

\section{Involvement of 5-LOX and leukotrienes in $\mathrm{I}_{M}$ increase}

To investigate further the LOX pathways, we superfused two specific 5-LOX inhibitors, 5,6-methanoleukotriene $A_{4}$ methylester (MLTA; $10 \mu \mathrm{M}$ ) and 5,6-dehydroarachidonic acid (DHAA; $10 \mu \mathrm{M})$. Both substances completely blocked the $I_{\mathrm{M}}$-augmenting effects of SS (five cells; Fig. 13A,B) and AA (four cells; Fig. 13B); however, like NDGA, they did not fully reverse the overall SS- 
Figure 9. Averaged effects of SS $(n=$ $33)$ or AA $(n=28)$ on $I_{M}$ kinetics. Time constants measured from $I_{\mathrm{M}}$ relaxations induced by hyperpolarizing steps from a mean holding potential of $-43 \mathrm{mV}$. $I_{\mathrm{M}}$ augmentation elicited by SS or AA is associated with a $23-30 \%$ increase in the $I_{\mathrm{M}}$ inactivation time constant. This effect was reversed on washout (not shown).

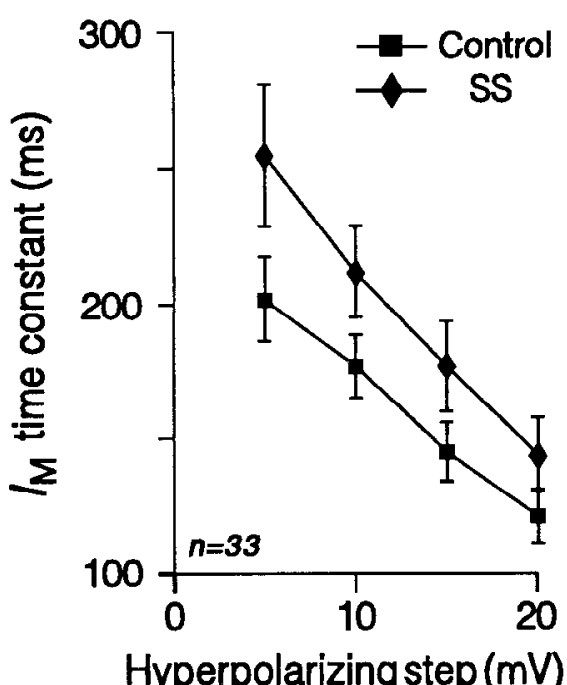

Hyperpolarizing step (mV)

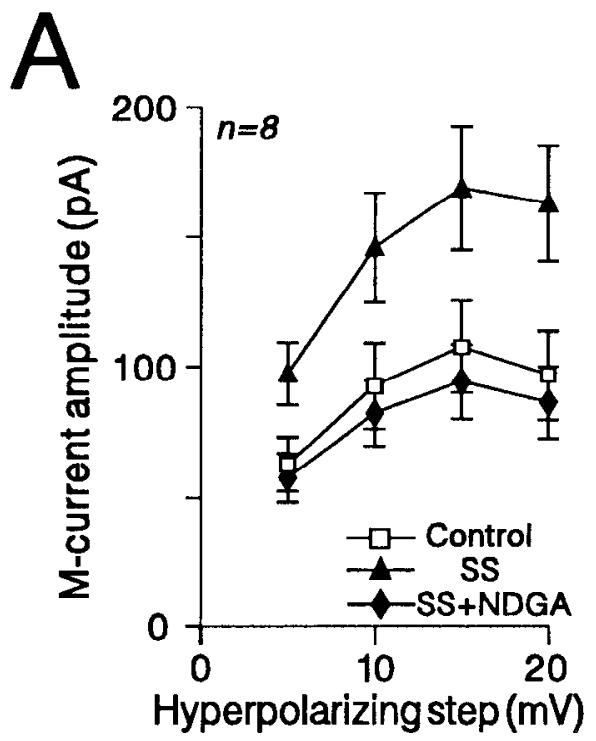

Figure 10. Action of NDGA, an LOX inhibitor, on SS and AA effects. $A$, NDGA completely reverses SS-(left) or AA- (right) induced $I_{\mathrm{M}}$ increase, implying that some further metabolite(s) of AA mediates the $I_{\mathrm{M}}$ increase. $B, \mathrm{Al}-$ though NDGA reduces the outward steady-state current induced by SS (left) or AA (right), it does not fully bring the current back to control level. Some residual outward current remains within the range of potentials tested (see also Fig. 12).
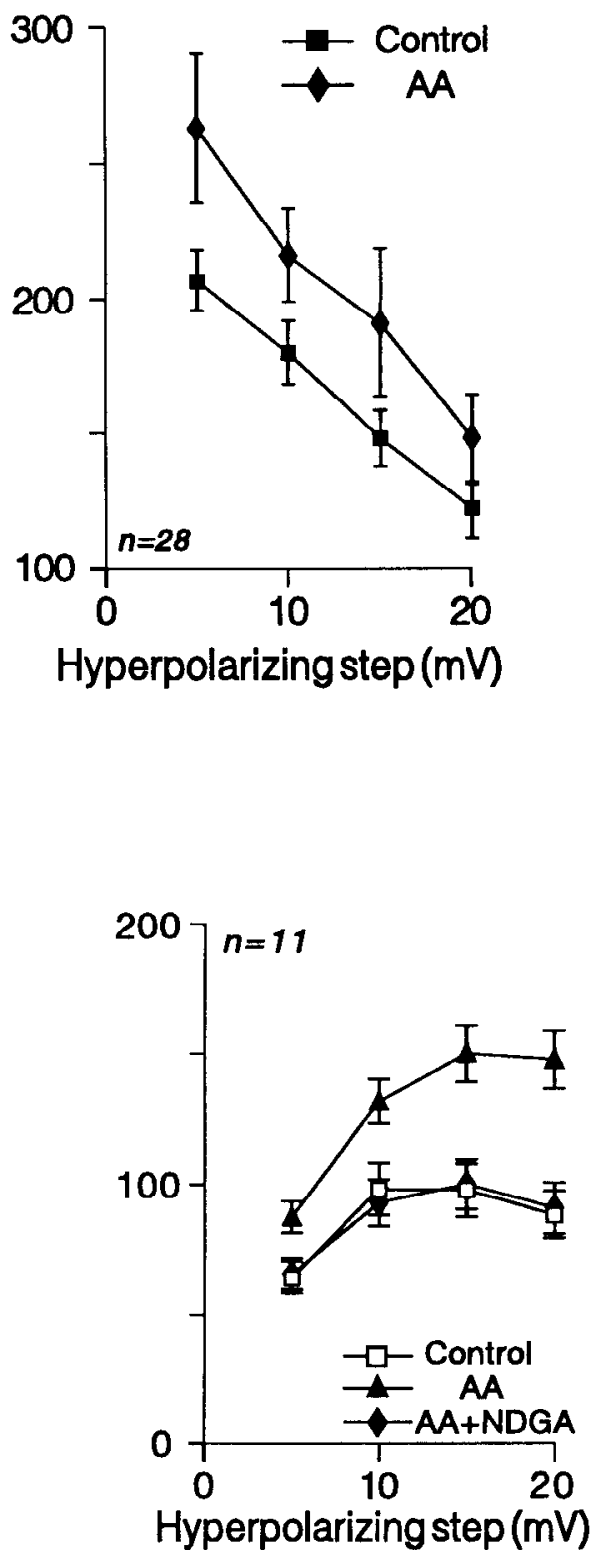

Hyperpolarizingstep (mV)

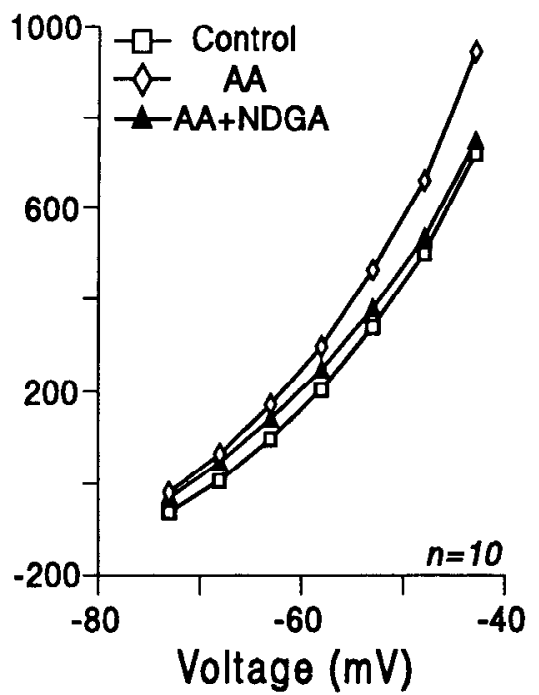



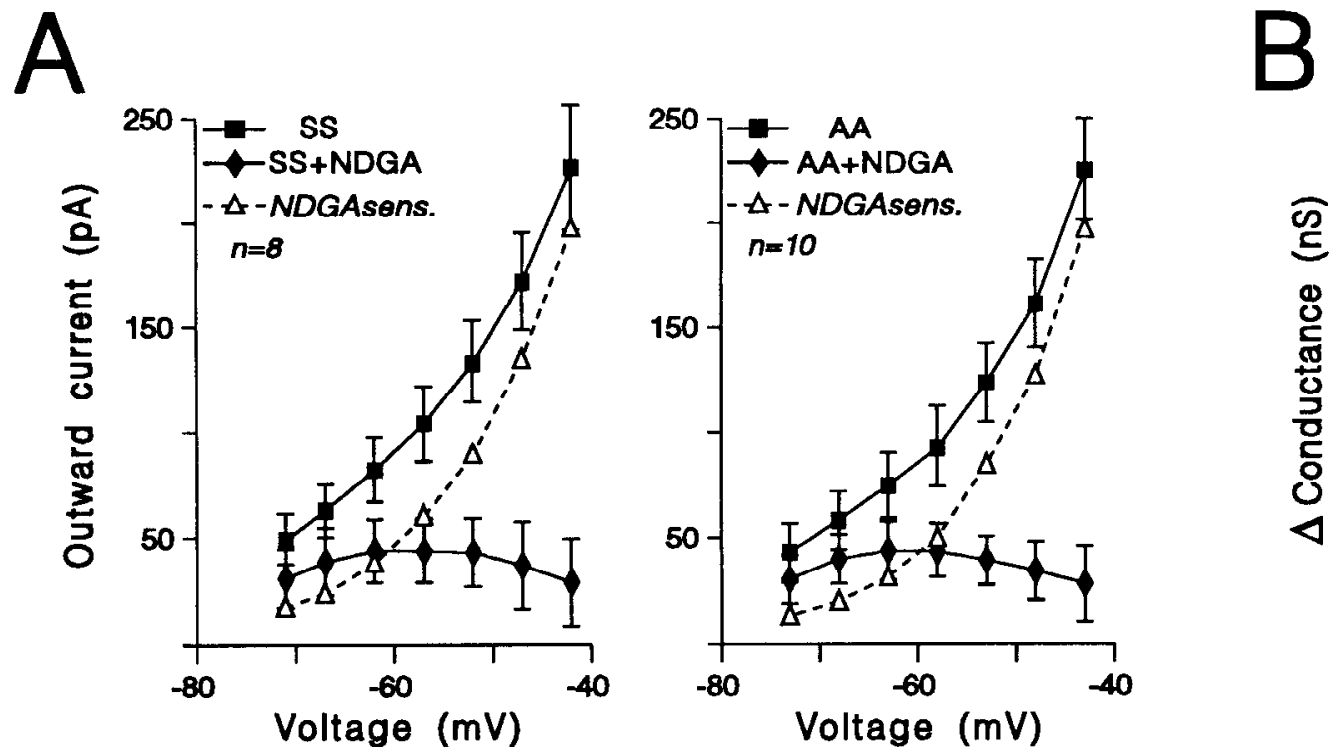

Figure 11. NDGA reveals more than one component in SS and AA effects. A, Graph of the net outward current induced by SS (left) and AA (right) before and during NDGA (data obtained from Fig. $11 \mathrm{~B}$ by subtracting steady-state currents). Application of SS or AA together with NDGA leaves a residual current. The NDGA-sensitive current (NDGA sens., broken line) represents the amount of SS or AA induced outward current blocked by NDGA, and is obtained by subtracting the residual current (SS+NDGA or AA+NDGA) from the total outward current evoked by either SS or AA. $B$, Conductance calculated from the NDGA-sensitive component of SS and AA effects $(N D G A$ sens. from $A)$, with an extrapolated reversal potential of -82 and $-83 \mathrm{mV}$ for SS and AA, respectively. This component of SS and AA effects exhibits a conductance increase of up to $3.5 \mathrm{nS}$, is voltage dependent, and activates around $-65 \mathrm{mV}$, implying equivalence to $I_{\mathrm{M}}$.

and AA-induced outward current (SS: four of five cells, Fig. 13C; AA: four of four cells, data not shown), leaving a residual current of $25-45 \mathrm{pA}$ (compare Figs. $11 \mathrm{~A}, 13 \mathrm{C}$ ).

The involvement of the 5-LOX pathway in $I_{\mathrm{M}}$ augmentation led us to test the leukotrienes. The initial product, leukotriene $\mathrm{A}_{4}\left(\mathrm{LTA}_{4}\right)$, can be transformed to $\mathrm{LTB}_{4}$ or $\mathrm{LTC}_{4}$. Superfusion of $\mathrm{LTC}_{4}(5-8 \mu \mathrm{M})$, even in the presence of NDGA (coperfused to prevent endogenous generation of AA metabolites), mimicked the action of SS and AA in augmenting both $I_{\mathrm{M}}$ and input conductance, and in eliciting an outward steady-state current at depolarized potentials (four of five cells; Fig. 14). LTB $_{4}$ (15-30 $\mu \mathrm{M}$ ) had no significant effect on these measures in three of four cells (data not shown), although it clearly increased $I_{\mathrm{M}}$ in one cell.

\section{Discussion}

SS hyperpolarizes central neurons in several preparations by activating a $\mathrm{K}^{+}$conductance. This $\mathrm{K}^{+}$current is outwardly rectifying in solitary tract complex (STC) (Jacquin et al., 1988), hippocampus (Schweitzer et al., 1990), and neocortex (Wang et al., 1989) and involves $I_{\mathrm{M}}$ in the STC and hippocampus but not in the neocortex. SS acts on an inward-rectifying conductance in locus coeruleus (Inoue et al., 1988) and possibly in dorsolateral septal nucleus (Twery and Gallagher, 1989). In the present study, we have analyzed the overall effects of SS in hippocampal pyramidal neurons and have (1) quantified the SS augmentation of $I_{\mathrm{M}}$ and the outward rectification, and detected an increase in its kinetics by SS and AA; (2) performed studies that largely exclude SS actions on some other conductances; (3) uncovered another outward-current effect of SS in hippocampus that may be activated by AA itself; and (4) provided further evidence for mediation of the $I_{\mathrm{M}}$ effect by an AA metabolite, probably a leukotriene.

\section{Selectivity of SS effects on the M-current}

Three major points demonstrate that the $I_{\mathrm{M}}$ effect of SS does not arise from actions on $I_{\mathrm{Q}}$ : (1) in contrast to $I_{\mathrm{Q}}$, the SS-enhanced inward $I_{\mathrm{M}}$ relaxations are larger at more depolarized potentials and show a greater ohmic step at hyperpolarizing command onset than at command offset; (2) Cs ${ }^{+}$blocks $I_{\mathrm{Q}}$ but not $I_{\mathrm{M}}$ nor the augmenting effect of SS on $I_{\mathrm{M}}$; (3) CCh (and Ba+ Moore et al., 1988) block the $I_{\mathrm{M}}$ relaxation and its augmentation by SS, but not the $I_{\mathrm{Q}}$ relaxation. Another potential site of action of SS is on an anomalous or inwardly rectifying $\mathrm{K}^{+}$current that could be distinct from $I_{\mathrm{Q}}$. Such inward rectifying currents are increased in some central neurons by SS, but these currents are sensitive to $\mathrm{Cs}^{+}$(Inoue et al., 1988). Indeed, we now have evidence that both SS and AA can elicit an outward current with properties distinct from $I_{\mathrm{M}}$. Ilowever, this current is rather small (30-50 pA), and current-voltage relationships before and during SS superfusion do not show much difference in the hyperpolarized voltage range. This contrasts with the effects of the GA$\mathrm{BA}_{\mathrm{B}}$ receptor agonist baclofen, which augments inward rectifcation and elicits a pronounced divergence of the current-voltage curves in the hyperpolarized range (S. Madamba and G. R. Siggins, unpublished observations; see Andrade et al., 1986). SS has also been shown to increase an outward $\mathrm{K}^{+}$current in neocortical neurons in culture (Wang et al., 1989). However, this effect is insensitive to $\mathrm{CCh}$, whereas the SS effect in hippocampus is blocked by this muscarinic agonist.

Other possible sites of SS action are large inward currents carried by, for example, $\mathrm{Ca}^{2+}$ or $\mathrm{Na}^{+}$, also possibly unclamped at remote (dendritic) sites. SS has been reported to diminish $\mathrm{Ca}^{2+}$ currents in cell lines (Ikeda and Schofield, 1989) and, more recently, in neocortical neurons in culture (Wang et al., 1990). AA has also been reported to inhibit $\mathrm{Ca}^{2+}$ currents in $\mathrm{CA} 1$ 

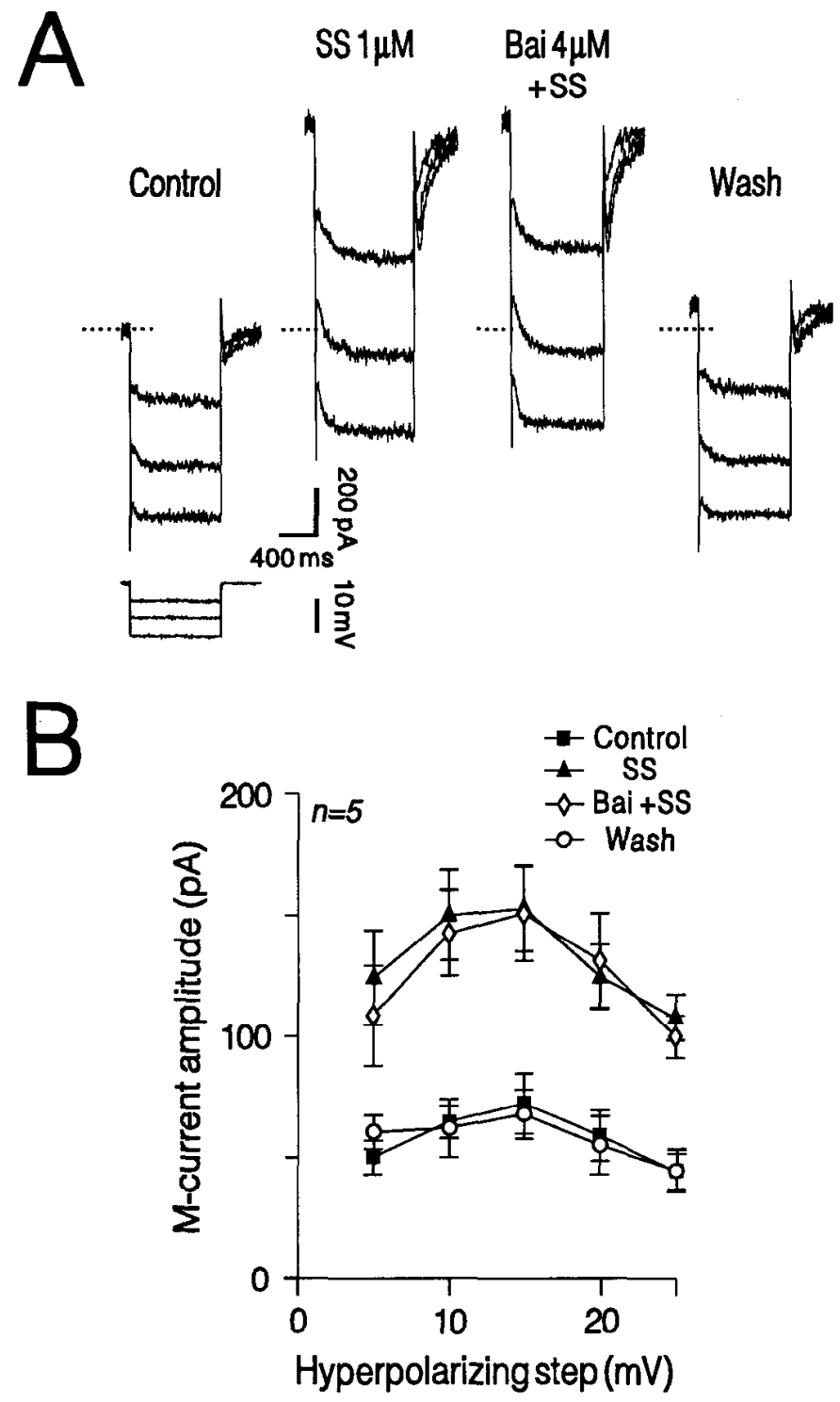

Figure 12. Effect of baicalein (Bai), a 12-LOX inhibitor, on SS effects. $A$, Current records: baicalein $4 \mu \mathrm{M}$, added for $7 \mathrm{~min}$ to the perfusate containing SS, does not alter the SS-induced $I_{\mathrm{M}}$ or conductance increase, or the outward steady-state current. Subsequent washout of both SS and baicalein with ACSF alone for 16 min reverses the SS effects. $B$, Plots of average $I_{\mathrm{M}}$ relaxations obtained with several different voltage commands. Baicalein did not reduce the SS-induced $I_{M}$ increase in any of these five cells. In four of these cells, baicalein was applied after SS as in $A$. In one of these cells, baicalein was applied for $8 \mathrm{~min}$ before the coadministration of SS; this cell also showed no alteration of the SS induced $I_{\mathrm{M}}$ increase. Washout of all drugs returned the mean $I_{\mathrm{M}}$ to control levels.

neurons in culture, possibly via protein kinase $\mathrm{C}$ activation (Keyser and Alger, 1990). However, in our studies, CA1 pyramidal neurons still showed SS augmentation of $I_{\mathrm{M}}$ after blockade of $\mathrm{Na}^{+}$- and $\mathrm{Ca}^{2+}$-dependent spikes with TTX, QX-314, and $\mathrm{Cd}^{2+}$. Furthermore, our observations that SS did not consistently alter $\mathrm{Ca}^{2+}$-dependent spikes in current clamp, or the inward currents (thought to be $I_{\mathrm{L}}$ ) evoked by depolarizing commands in the whole-cell configuration, also argue against a SS effect on $\mathrm{Ca}^{2+}$ conductances.

Another possible site of SS action is on conductances under- lying the posttrain AHP, such as $I_{\mathrm{AHP}}$ or $I_{\Gamma}$. However, in previous studies we did not see a consistent effect of SS on the AHPs themselves (Moore et al., 1988). Furthermore, SS effects and $I_{\mathrm{M}}$ itself, but not $I_{\mathrm{C}}$ (Madison et al., 1987), are blocked by $\mathrm{CCh}$. In the present study, superfusion of $\mathrm{Cd}^{2+}$, known to block several types of AHP currents (as well as other $\mathrm{Ca}^{2+}$-dependent precesses), did not alter SS-induced $I_{\mathrm{M}}$ increases. Nonetheless, a thorough voltage-clamp ("hybrid-clamp") study of the underlying currents has not been carried out, partly because of the likelihood that there will also be a contribution of $I_{M}$ to such conductances (Storm, 1989). Thus, we cannot completely eliminate the possibility that an AHP current is involved.

\section{Second messenger mediation of SS effects}

SS has been shown to inhibit adenylate cyclase in many preparations (see, e.g., Chneiweiss et al., 1985; Wang et al, 1989). Thus, cAMP would seem an obvious candidate for mediation of SS effects. However, analogs of cAMP did not markedly alter resting properties or the $I_{M}$ of CAl cells in our studies. They induced a small inward current similar to that previously described for hippocampal neurons (Madison and Nicoll, 1986). Altcrnatively, the carly, small steady-state outward current elicited by 8 -Br-cAMP could be due to a brief effect on extracellular adenosine receptors. It should be noted that the electrophysiological effects of SS in neocortical neurons described by Wang et al. (1989) also were independent of cAMP.

Thus, cAMP does not seem to be involved in the mediation of SS-effects in hippocampus. Other investigators have examined the role of additional second messenger systems in $I_{\mathrm{M}}$ regulation. Diacylglycerol and protein kinase C do not affect $I_{\mathrm{M}}$ (Malenka et al., 1986), but inositol triphosphate, a product of PLC, has been shown to decrease $I_{\mathrm{M}}$ and is thought to be the mediator for the muscarinic inactivation of $I_{\mathrm{M}}$ (Dutar and Nicoll, 1988). A role for intracellular $\mathrm{Ca}^{2+}$ in $I_{\mathrm{M}}$ regulation is also now becoming apparent (see Further aspects of second messenger mediation, below).

$A A$ and its metabolites mediate SS effects. Our combined data (see also Schweitzer et al., 1990) implicates AA and its metabolites as strong candidates for mediation of SS effects. The parallel mimicry of all SS effects by exogenously applied AA is consistent with a role for AA as an intracellular mediator. Thus, SS and AA superfusion augments $I_{\mathrm{M}}$ amplitude $(55-60 \%$ and $55-75 \%$, respectively) and kinetics $(20-27 \%$ and $23-31 \%$, respectively) to the same extent. SS and AA elicit a similar outward steady-state current increasing with depolarization (221 $\mathrm{pA}$ and $233 \mathrm{pA}$, respectively, at $-43 \mathrm{mV}$ holding potential). Although it could be argued that the concentration of AA we used is high, it should be noted that because of the adsorption of fatty acids, the actual concentrations of AA surrounding the cell in our experiments are certainly lower than the calculated concentrations in the chambers. It is likely that the amount of AA gaining access to the neuronal membrane is $<5 \%$ of that in the buffer (Freeman et al., 1990). Thus, presumably less than 6 $\mu \mathrm{M}$ AA reached the neuronal membrane.

Our other pharmacological findings further support the involvement of AA in mediating SS effects. Thus, both the PLA inhibitors $4 \mathrm{BPB}$ and quinacrine completely blocked all the SS effects. The antagonism appeared identical, in spite of differences in the site of action of each of these inhibitors: 4BPB inhibits $\mathrm{PLA}_{2}$ (but not PLC in hippocampus; see Okada et al., 1989) by binding to the enzyme, whereas quinacrine interacts with the phospholipid substrate (see Blackwell and Flower, 1983). 
A
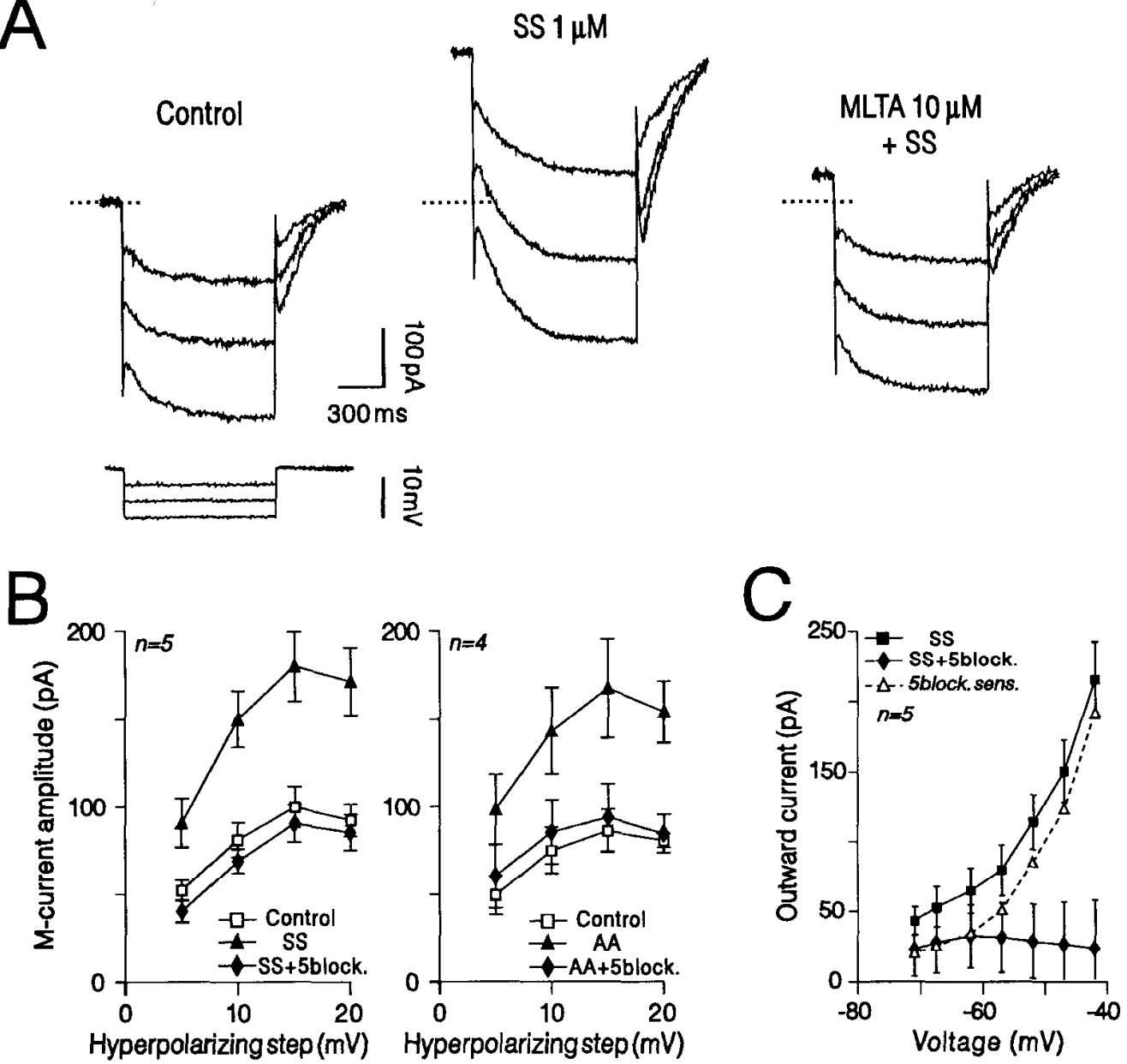

Figure 13. 5-LOX metabolites are implicated in SS-induced $I_{\mathrm{M}}$ auginentation, $A$, Current recording of a CA 1 neuron held at $-43 \mathrm{mV} . I_{\mathrm{M}}$ amplitude is increased by SS superfusion $(6 \mathrm{~min})$, together with a pronounced outward steady-state current (broken line is control holding current). Subsequent superfusion of MLTA, a specific 5-LOX inhibitor (together with SS), abolishes $I_{\mathrm{M}}$ augmentation but does not completely bring the steady-state current back to control level. RMP was $-67 \mathrm{mV}$ for this cell. Voltage protocol is shown at lower left. $B, I_{\mathrm{M}}$ augmentation by either SS (left; five cells) or AA (right; four cells) is completely abolished by either of the specific 5-LOX inhibitors (5block; MLTA or DHAA). $C$, As with NDGA (see Fig. 12A), the net SS-induced outward current is partially reversed by the 5-LOX inhibitors. Current subtraction reveals a voltage-dependent component sensitive to 5 - $\mathrm{LOX}$ inhibitors that activates around $-65 \mathrm{mV}$ (i.e., $I_{\mathrm{M}}$ ).
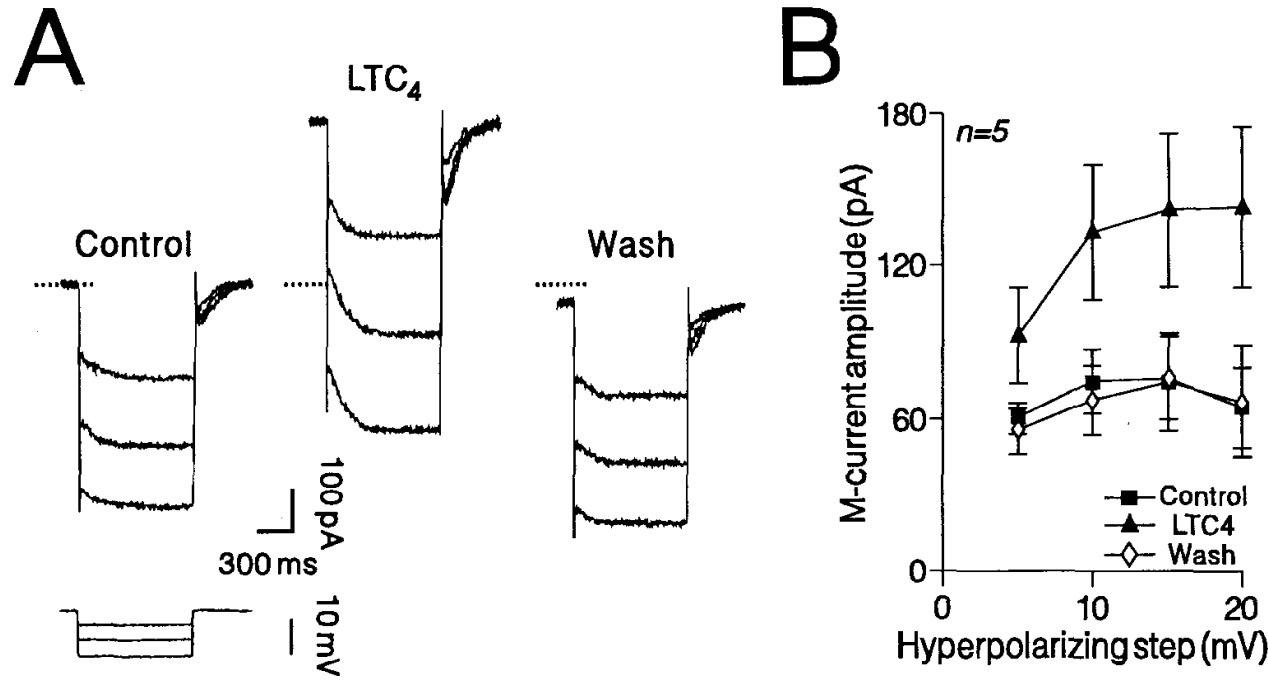

Figure 14. $\mathrm{LTC}_{4}$ mimics $\mathrm{AA}$ and $\mathrm{SS}$ effects on $I_{\mathrm{M}} \cdot A$, Digitized current records from a CAl pyramidal neuron. Superfusion of $\operatorname{LTC}_{4}(5 \mu \mathrm{M})$ in the presence of NDGA $(10 \mu \mathrm{M})$ augments $I_{\mathrm{M}}$ and causes an outward steady-state current (broken line is control holding current) associated with an increase in input conductance. Washout brings all current measures back to near normal levels. Voltage protocol for all current records shown at lower left. $B$, Average of $I_{\mathrm{M}}$ amplitudes for five cells tested with $\mathrm{LTC}_{4}$, using holding potentials of about $-45 \mathrm{mV}$, and the same drug protocol as in $A$. A verage $I_{\mathrm{M}}$ is significantly increased by $\mathrm{LTC}_{4}(P<0.05$, two-factor ANOVA for repeated measures, Newman-Keuls post hoc test). 


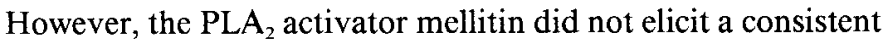
effect on $I_{\mathrm{M}}$, but evoked a delayed dramatic inward current without recovery, possibly due to a lysis of the membrane lipids by mellitin (see Katsu et al., 1989). Further support of the role for AA in SS effects is a recent report showing that SS activates $P L \Lambda_{2}$ and AA release in astrocytes (Marin et al., 1991).

$L O X$ metabolites mediate $\mathrm{I}_{M}$ augmentation. Our studies of the AA pathways suggest a role for LOX metabolites of AA in the SS- $I_{\mathrm{M}}$ effect. The LOX inhibitor NDGA completely antagonizes SS- and AA-induced $I_{\mathrm{M}}$ augmentation. Concomitantly, NDGA greatly reduces the SS- and AA-induced outward steadystate current. Thus, it seems that the NDGA-sensitive outward steady-state current is entirely due to $I_{\mathrm{M}}$, since the threshold of activation, voltage dependency, and NDGA blockade of this outward current correlate with these properties of the $I_{\mathrm{M}}$. Furthermore, our conductance calculations reveal an increase of M-conductance of 3-4 nS with AA (Fig. 7C) or SS (Schweitzer et al., 1990), values very similar to those found for the SS- or AA-induced outward current sensitive to NDGA (Fig. 11B). The different inhibitors of the AA cascade we used only blocked the SS-induced outward current and $I_{M}$ increase, without affecting the basal currents. Thus, AA and its metabolites may be involved only in the SS effects and do not seem to control resting properties.

There are several LOXs; the two major ones are 5-LOX and 12-LOX. Our findings that specific 5-LOX but not 12-LOX inhibitors antagonize both SS- and AA-induced $I_{\mathrm{M}}$ effects are consistent with mediation of SS- $I_{\mathrm{M}}$ effects by 5-LOX metabolites. As with NDGA, a residual outward current remains when 5-LOX blockers are added together with SS or AA, suggesting again some effect of AA itself. The role of 5-LOX and leukotrienes in the SS- $I_{\mathrm{M}}$ effect is supported further by our finding that $\mathrm{LTC}_{4}$ application leads to $I_{\mathrm{M}}$ effects similar to those obtained with AA and SS. Leukotrienes are synthesized in several brain regions, including hippocampus (Dembinska-Kiec et al., 1984; Lindgren et al., 1984). LTC 4 can be metabolized further to $\mathrm{LTD}_{4}$ and $\mathrm{LTE}_{4}$ (reviewed by Samuelsson et al., 1987), which could also be involved in the SS- $I_{M}$ effect. However, binding sites for $\mathrm{LTB}_{4}$ and $\mathrm{LTE}_{4}$ are weak and those for $\mathrm{LTD}_{4}$ undetectable, suggesting that $\mathrm{LTC}_{4}$ may represent the most active metabolite in brain. Interestingly, specific $\mathrm{LTC}_{4}$ binding sites are found in several brain areas and are among the most numerous in brainstem and hippocampus (Schalling et al., 1986), the two areas where SS has been shown to increase $I_{\mathrm{M}}$ (Jacquin et al., 1988; Moore et al., 1988).

The 12-LOX metabolites have been shown to be involved in FMRFamide and histamine effects in Aplysia (Piomelli et al., $1987 \mathrm{a}, \mathrm{b})$. Here, the FMRFamide effect could be mediated directly by 12-HPETE (Buttner et al., 1989) or a heme-catalyzed product (Belardetti et al., 1989). However, in our experiments, the 12-LOX inhibitor baicalein had no effect on SS responses. In accord with this finding, superfusion of the 12-LOX product 12-HPETE gave inconsistent results, and in no case did it alter $I_{\mathrm{M}}$. Still, given the transient chemical nature of this short-lived intermediate metabolite (Piomelli and Greengard, 1990) compared to AA and $\mathrm{LTC}_{4}$ (Samuelsson et al., 1987), conclusions regarding these negative findings should be tentative when using a brain slice preparation, where drugs need 1-2 min to reach the recorded cell. Other studies have shown that AA causes hyperpolarization and increased posttrain AHP size in CAl hippocampal neurons, but without change in input resistance (Carlen et al., 1989). These effects were reproduced by the pep- tidyl form of 8-HEpETE (8-hydroxy-1 1,12-epoxy-5,9,14-icosatrienoic acid or hepoxillin $\mathrm{A}_{3}$ ), a 12-LOX metabolite, although without recovery on washout. Interestingly, the formation of this compound is analogous to that of $\mathrm{LTC}_{4}$, in that both products are produced by a glutathione-conjugating system (PaceAsciak et al., 1990).

$A$ second SS effect. Effects of the LOX inhibitor NDGA, as well as MLTA and DHAA, also reveal that SS acts on another conductance. The persistence of a small current in the presence of LOX inhibitors and the lack of effect of the COX inhibitor indomethacin suggest that this effect is not mediated by an AA metabolite, but most likely by the fatty acid itself. AA and certain fatty acids have been shown to alter electrophysiological cell properties in peripheral tissues by acting on ionic currents (reviewed by Ordway et al., 1991). Therefore, the NDGA-resistant hyperpolarizing effect of AA could be due to a direct interaction with a channel or alteration of the membrane lipid bilayer. This current is rather small but appears to play a major role in the hyperpolarizing effect seen at rest. Interestingly, the hyperpolarizing effect (40-90 pA outward current) of SS and AA on a few neurons not responding with $I_{\mathrm{M}}$ augmentation resembles the NDGA-resistant current, and indeed also was resistant to LOX and COX inhibition. The properties of the NDGA-resistant current are still unclear: it could be an inwardly rectifying current, or perhaps a leak current such as that reduced by muscarinic agonists in hippocampal neurons (Madison et al., 1987). The unusual nonlinearity of this current could also be related to some uncharacterized dendritic conductance (see Benson et al., 1988). In fact, it is possible that if the underlying conductance is generated far away on the dendritic tree, it may not be properly clamped, especially in the depolarized potentials.

We also examined a possible role of the COX pathway. The lack of effect of the prostaglandins as well as indomethacin alone on $I_{\mathrm{M}}$ suggests that COX metabolites are probably not linked to the $I_{\mathrm{M}}$ augmentations elicited by SS or AA. Interestingly, indomethacin has been shown to increase $\mathrm{LTC}_{4}$ levels in rat brain (Dembinska-Kiec et al., 1984). Thus, the potentiations we saw with indomethacin applied together with SS or AA could arise from $\mathrm{COX}$ inhibition, leading to shunting of increased AA toward the LOX pathway (see Higgs and Vane, 1983). However, we cannot disregard a possible effect on $I_{\mathrm{M}}$ of some other COX metabolites not yet tested, or possible inhibitory effects of prostanoids on the LOX pathway. A dual role of COX and LOX mctabolites has been described for the modulation of an inwardly rectifying $\mathrm{K}^{+}$current in atrial cells (Scherer and Breitwieser, 1990). The partial later inhibition of SS effects by indomethacin we saw in some cells may reflect nonspecific

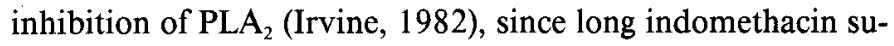
perfusions never reduced $\mathrm{AA}$-induced $I_{\mathrm{M}}$ increase.

The data reported here and elsewhere (Schweitzer et al., 1990) provide new electrophysiological evidence for eicosanoid mediation of a transmitter effect in a vertebrate central neuron. Piomelli et al. $(1987 \mathrm{a}, \mathrm{b})$ previously showed that 12 -LOX metabolites may mediate FMRFamide effects on a $\mathrm{K}^{+}$current, and hyperpolarizations elicited by histamine, in Aplysia neurons. Prostaglandins have been implicated in mediation of vasoactive intestinal peptide (VIP) biochemical effects in brain slices (Schaad et al., 1987), whereas LOX products may regulate VIP release (Martin and Magistretti, 1989). Similarly, a product of the epoxygenase pathway for AA, 5,6-epoxyeicosatrienoic acid, induces $S S$ release in hypothalamus (Capdevila et al., 1983). Thus, 
as with VIP, two different AA pathways appear to be involved in the release of SS on the one hand and its electrophysiological effects on the other.

$M$-current kinetics. Considering that our studies were done at a higher temperature, the $I_{\mathrm{M}}$ time constant $(\tau)$ values in the present study are consistent with those of Halliwell and Adams (1982). These authors reported values of $267-303 \mathrm{msec}$ at -50 $\mathrm{mV}$ and $118-176 \mathrm{msec}$ at $-60 \mathrm{mV}$ (temperature of $23^{\circ} \mathrm{C}$ ) in guinea pig hippocampus, with a $Q_{10}$ of about 5 around $25^{\circ} \mathrm{C}$. We found that both SS and AA significantly increased $\tau$ for the $I_{\mathrm{M}}$ relaxations in CAI pyramidal neurons. The increase with $\mathrm{SS}$ or AA compared to control conditions did not reach significance in our previous report (Schweitzer et al., 1990), because of the variability in $\tau$-values and the smaller number of cells in our earlier sample. Interestingly, the $I_{\mathrm{M}}$ increase evoked by isoproterenol in smooth muscle is also associated with a $\tau$ increase (Sims et al., 1988), as is the $I_{M}$ augmentation (termed overrecovery) observed on washout of muscarine in sympathetic neurons (Marrion et al., 1991). The $\tau$ increase for $I_{M}$ we observe in pyramidal neurons with both SS and AA might represent a change of $\mathrm{M}$-channel properties due to a variation in intracellular $\mathrm{Ca}^{2+}$ concentrations (see Marrion et al., 1991). The isoproterenol effect on $\tau$ in smooth muscle cells appears to be mediated by cAMP, and is postulated to reflect a decrease in the closing rate constant for M-channels (Sims et al., 1988).

\section{Further aspects of second messenger mediation}

Using fura-2 measurements, Marrion et al. (1991) observed that $I_{\mathrm{M}}$ augmentation (over-recovery) in sympathetic ganglia after muscarine washout is associated with a moderate increase of intracellular $\mathrm{Ca}^{2+}$ concentration (higher internal $\mathrm{Ca}^{2+}$ elevation blocks $I_{\mathrm{M}}$ ). It is possible that in a process of muscarinic acti-

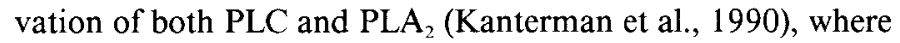
internal $\mathrm{Ca}^{2+}$ would rise and then fall, PLC may inactivate first because of a lower sensitivity to intracellular $\mathrm{Ca}^{2+}$ than $\mathrm{PLA}_{2}$.

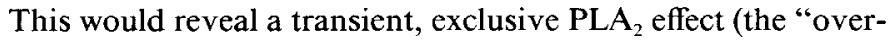
recovery"), before inactivation of this enzyme as the internal $\mathrm{Ca}^{2+}$ concentration returns to basal levels. More recent data also have shown augmentation of $I_{\mathrm{M}}$ by intracellular $\mathrm{Ca}^{2+}$ injection; this effect is blocked by NDGA and mimicked by AA (Yu et al., 1991). Thus, internal $\mathrm{Ca}^{2+}$ seems to play a key role in $I_{M}$ regulation, especially when considering possible differential sensitivities to $\mathrm{Ca}^{2+}$ of the enzymes that may be involved (PLA PLC, protein kinase C), acting in opposite directions through the metabolites they generate (in hippocampal CAl neurons, PLC and inositol triphosphate vs PLA $\mathrm{A}_{2}$ and AA metabolites).

It is also possible that a GTP-binding protein may be involved

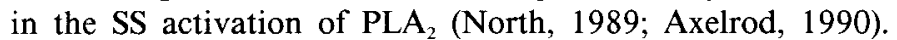
Biochemical studies have shown that SS receptors are linked to G-proteins in brain (see Law et al. 1991). Further studies will be required to determine if the SS effects described here involve one or more G-proteins. Furthermore, the exact metabolite or metabolites involved in hippocampal SS effects on $I_{M}$ are not known, although our data with LTC $_{4}$ suggest that a leukotriene is the best candidate. Additional support of this idea must await localization (e.g., by immunocytochemistry or in situ hybridization) of the relevant enzymes or their products in hippocampal neurons. Given their great membrane permeability, eicosanoids, unlike most other messengers, can leave the cell in which they are generated and act as first messengers on neighboring cells (Piomelli et al., 1987a; Piomelli and Greengard, 1990; Shimizu and Wolfe, 1990). Thus, they could act on the M-chan- nels and other conductances by either an intracellular or an extracellular route. Therefore, presynaptic or feedback effects cannot be excluded. Studies using intracellular drug application are planned to evaluate these alternatives.

In this regard, there is now considerable evidence that AA and/or PLA (and possibly some LOX metabolites) play some role in hippocampal CA1 long-term potentiation (LTP), the electrophysiological model of learning and memory. Thus, (1) AA produces a long-lasting enhancement of synaptic transmission (Williams et al., 1989; Drapeau et al., 1990) and increases NMDA currents (Miller et al., 1992); (2) inhibitors of PLA can $_{2}$ prevent expression of LTP (Okada et al., 1989; Williams and Bliss, 1989; Drapeau et al., 1990); and (3) both NMDA (thought to be the trigger for LTP) and LTP itself increase the release and postsynaptic membrane levels of AA in hippocampal tissue (Sanfeliu et al., 1990; Clements et al., 1991). The view of some researchers (see, e.g., Clements et al., 1991) is that AA or a metabolite is generated postsynaptically but diffuses to presynaptic glutaminergic terminals to enhance transmitter release (but see O'Dell et al., 1991, for another mechanism involving nitric oxide). Although our findings of inhibitory (hyperpolarizing) effects of $\mathrm{AA}$ and $\mathrm{LTC}_{4}$ are not entirely consistent with enhancement of synaptic transmission, the AA metabolite(s) may have a different effect on presynaptic terminals or elsewhere than at postsynaptic CA1 pyramidal neurons. The recent finding that AA (and also SS via PLA ; Marin et al., 1991) causes a prolonged inhibition of glutamate uptake into glia (Barbour et al., 1989) is consistent with this interpretation.

The exact physiological role and sites of action of the relevant lipid(s) in hippocampus cannot be stated at this time. However, our findings do suggest that, as in some invertebrate neurons (Piomelli et al., 1987a; Belardetti and Siegelbaum, 1988), a single ion channel type (the M-channel) in mammalian central neurons can be regulated in opposing or reciprocal directions by two different ligands-SS and $\mathrm{ACh}$-acting through different second messenger systems. These bidirectional regulatory mechanisms should provide sensitive biasing of ion channel activity, and thus of neuronal excitability. Possible cross-talk between the intracellular mediators adds further complexity. In addition, the present studies now suggest a second SS-sensitive conductance (NDGA resistant) in most of the same cells exhibiting $I_{\mathrm{M}}$ augmentation. Hence, in these cells SS receptors may not only converge with another receptor class (muscarinic) onto a single channel type; SS may also diverge to act on another SS-receptorion channel system with different, but still hyperpolarizing, properties. This latter SS substrate appears to require at least one less enzyme for its function than the M-channel effect, and therefore may be subject to quite different regulatory factors.

\section{References}

Adams PR, Brown DA (1982) Synaptic inhibition of the M-current: slow excitatory post-synaptic potential mechanism in bullfrog sympathetic neurones. J Physiol (Lond) 332:263-272.

Adams PR, Brown DA, Constanti A (1982) M-Currents and other potassium currents in bullfrog sympathetic neurones. J Physiol (Lond) 330:537-572.

Andrade R, Malenka RC, Nicoll RA (1986) A G-protein couples serotonin and $\mathrm{GABA}_{\mathrm{B}}$ receptors to the same channels in hippocampus. Science 234:1261-1265.

Axelrod J (1990) Receptor-mediated activation of phospholipase A2 and arachidonic acid release in signal transduction. Biochem Soc Trans 18:503-508.

Bakst I, Avendano C, Morrison JH, Amaral DG (1986) An experi- 
mental analysis of the origins of somatostatin-like immunoreactivity in the dentate gyrus of the rat. J Neurosci 6:1452-1462.

Barbour B, Szatkowski M, Ingledew NM, Attwell D (1989) Arachidonic acid induces a prolonged inhibition of glutamate uptake into glial cells. Nature 342:918-920.

Belardetti F, Siegelbaum SA (1988) Up- and down-modulation of single $\mathrm{K}^{+}$channel function by distinct second messengers. Trends Neurosci 11:232-238.

Belardetti F, Campbell WB, Falck JR, Demontis G, Rosolowsky M (1989) Products of heme-catalyzed transformation of the arachidonate derivative 12-HPETE open S-type $\mathrm{K}^{+}$channels in Aplysia. Neuron $3: 497-505$.

Benson DM, Blitzer RD, Landau EM (1988) An analysis of the depolarization produced in guinea-pig hippocampus by cholinergic receptor stimulation. J Physiol (Lond) 404:479-496.

Blackwell GJ, Flower RJ (1983) Inhibition of phospholipase. Br Med Bull 39:260-264.

Blanton MG, LoTurco JJ, Kriegstein AR (1989) Whole cell recording from neurons in slices of reptilian and mammalian cerebral cortex. J Neurosci Methods 30:203-210.

Brown DA (1988) M-Currents: an update. Trends Neurosci 11:294299.

Brown DA, Adams PR (1980) Muscarinic suppression of a novel voltage-sensitive $\mathrm{K}^{+}$current in a vertebrate neurone. Nature 283: 673-676.

Brown DA, Marrion NV, Smart TG (1989) On the transduction mechanism for muscarinic-induced inhibition of M-current in cultured rat sympathetic neurones. J Physiol (Lond) 413:469-488.

Buttner N, Siegelbaum SA, Volterra A (1989) Direct modulation of Aplysia $\mathrm{S}^{-\mathrm{K}^{+}}$channels by a 12 -lipoxygenase metabolite of arachidonic acid. Nature 342:553-555.

Capdevila J, Chacos N, Falck JR, Manna S, Negro-Vilar A, Ojeda SR (1983) Novel hypothalamic arachidonate products stimulate somatostatin release from the median eminence. Endocrinology 113: $421-423$.

Carlen PL, Gurevich N, Wu PH, Su W-G, Corey EJ, Pace-Asciak CR (1989) Actions of arachidonic acid and hepoxilin A3 on mammalian hippocampal CA1 neurons. Brain Res 497:171-176.

Charpak S, Gähwiler BH, Do KQ, Knöpfel T (1990) Potassium conductances in hippocampal neurones blocked by excitatory aminoacid transmitters. Nature 347:765-767.

Chneiweiss H, Glowinski J, Premont J (1985) Modulation by monoamines of somatostatin-sensitive adenylate cyclase on neuronal and glial cells from the mouse brain in primary cultures. J Neurochem 44:1825-1831.

Clements MP, Bliss TVP, Lynch MA (1991) Increase in arachidonic acid concentration in a postsynaptic membrane following the induction of long-term potentiation in the dentate gyrus. Neuroscience 45: 379-389.

Connors BW, Prince DA (1982) Effects of local anesthetic QX-314 on the membrane properties of hippocampal pyramidal neurons. $J$ Pharmacol Exp Ther 220:476-481.

Crawley JN (1985) Comparative distribution of cholecystokinin and other neuropeptides. Ann NY Acad Sci 448:1-8.

Dembinska-Kiec A, Simmet T, Peskar BA (1984) Furmation of leukotriene $\mathrm{C}_{4}$-like material by rat brain tissue. Eur J Pharmacol 99:5762.

Dodd J, Kelly JS (1978) Is somatostatin an excitatory transmitter in the hippocampus? Nature 273:674-675.

Drapeau C, Pellerin L, Wolfe LS, Avoli M (1990) Long-term changes of synaptic transmission induced by arachidonic acid in the CA1 subfield of the rat hippocampus. Neurosci Lett 115:286-292.

Dutar P, Nicoll RA (1988) Classification of muscarinic responses in hippocampus in terms of receptor subtypes and second-messenger systems: electrophysiological studies in vitro. J Neurosci 8:4214-4224.

Epelbaum J (1986) Somatostatin in the central nervous system: physiological and pathological modifications. Prog Neurobiol 27:63-100.

Finkel AS, Redman SJ (1985) Optimal voltage clamping with single microelectrodes. In: Vollage and patch clamping with microelectrodes (Smith TG, Lecar A, Redman SJ, Gage PW, eds), pp 95-120. Baltimore: Williams \& Wilkins.

Freeman EJ, T'errian DM, Dorman KV (1990) Presynaptic facilitation of glutamate release from isolated hippocampal mossy fiber nerve endings by arachidonic acid. Neurochem Res 15:743-750.

Halliwell JV, Adams PR (1982) Voltage-clamp analysis of muscarinic excitation in hippocampal neurons. Brain Res 250:71-92.
Higgs GA, Vane JR (1983) Inhibition of cyclo-oxygenase and lipoxygenase. Br Med Bull 39:265-270.

Ikeda SR, Schofield GG (1989) Somatostatin blocks a calcium current in rat sympathetic ganglionic neurons. J Physiol (Lond) 409:221-240.

Inoue M, Nakajima S, Nakajima Y (1988) Somatostatin induces an inward rectification in rat locus coeruleus neurones through a pertussis toxin-sensitive mechanism. J Physiol (I ond) 407:177-198.

Irvine RF (1982) How is the level of free arachidonic acid controlled in mammalian cells? Biochem $\mathbf{J}$ 204:3-16.

Jacquin T, Champagnat J, Madamba SG, Denavit-Saubié M, Siggins GR (1988) Somatostatin depresses excitability in neurons of the solitary tract complex through hyperpolarization and augmentation of $I_{\mathrm{M}}$, a non-inactivating voltage-dependent outward current blocked by muscarinic agonists. Proc Natl Acad Sci USA 85:948-952.

Joëls M, Madamba SG, Moore SD, Morrison JH, Siggins GR (1990) Somatostatin immunohistochemistry of hippocampal slices with Lucifer yellow-stained pyramidal neurons responding to somatostatin. Regul Pept 28:215-221.

Johnston D, Brown TH (1983) Interpretation of voltage-clamp measurements in hippocampal neurons. J Neurophysiol 50:464-486.

Kanterman RY, Ma AL, Briley FM, Axelrod J, Felder CC (1990) Muscarinic receptors mediate the release of arachidonic acid from spinal cord and hippocampal neurons in primary culture. Neurosci Lett 118:235-237.

Katsu T, Kuroko M, Morikawa T, Sanchika K, Fujita Y, Yamamura H, Uda M (1989) Mechanism of membrane damage induced by the amphipathic peptides gramicidin $\mathbf{S}$ and melittin. Biochem Biophys Acta 983:135-141.

Keyser DO, Alger BE (1990) Arachidonic acid modulates hippocampal calcium current via protein kinase $\mathrm{C}$ and oxygen radicals. Neuron 5:545-553.

Law S, Manning D, Reisine T (1991) Identification of the subunits of GTP-binding proteins coupled to somatostatin receptors. J Biol Chem 266:17885-17894.

Lindgren JA, Hökfelt T, Dahlén S-E, Patrono C, Samuelsson B (1984) Leukotrienes in the rat central nervous system. Proc Natl Acad Sci USA 81:6212-6216.

Madison DV, Nicoll RA (1986) Cyclic adenosine 3',5'-monophosphate mediates $\beta$-receptor actions of noradrenaline in rat hippocampal cells. J Physiol (Lond) 372:245-259.

Madison DV, Lancaster B, Nicoll RA (1987) Voltage clamp analysis of cholinergic action in the hippocampus. J Neurosci 7:733-741.

Malenka RC, Madison DV, Andrade R, Nicoll RA (1986) Phorbol esters mimic some cholinergic actions in hippocampal pyramidal neurons. J Neurosci 6:475-480.

Mancillas J, Siggins GR, Bloom FE (1986) Somatostatin selectively enhances acetylcholine-induced excitations in rat hippocampus and cortex. Proc Natl Acad Sci USA 83:7518-7521.

Marin P, Delumeau JC, Tence M, Cordier J, Glowinsky J, Premont J (1991) Somatostatin potentiates the $\alpha_{1}$-adrenergic activation of phospholipase $\mathrm{C}$ in striatal astrocytes through a mechanism involving arachidonic acid and glutamate. Proc Natl Acad Sci USA 88:90169020.

Marrion NV, Zucker RS, Marsh SJ, Adams PR (1991) Modulation of M-current by intracellular $\mathrm{Ca}^{21}$. Neuron 6:533-545.

Martin J-L, Magistretti PJ (1989) Release of vasoactive intestinal peptide in mouse cerebral cortex: evidence for a role of arachidonic acid metabolites. J Neurosci 9:2536-2542.

Miller B, Sarantis M, Traynelis SF, Attwell D (1992) Potentiation of NMDA receptor currents by arachidonic acid. Nature 355:722-725.

Moore SD, Madamba SG, Joëls M, Siggins GR (1988) Somatostatin augments the $M$-current in hippocampal neurons. Science 239:278280.

Moore SD, Madamba SG, Siggins GR (1990) Ethanol diminishes a voltage-dependent $\mathrm{K}^{+}$current, the M-current, in CA 1 hippocampal pyramidal neurons in vitro. Brain Res 516:222-228.

Needleman P, Turk J, Jakschik BA, Morrison AR, Lefkowith JB (1986) Arachidonic acid metabolism. Annu Rev Biochem 55:69-102.

Nishiyama $M$, Okamoto $H$, Watanabe $T$, Hori $T$, Hada $T$, Ueda $N$, Yamamoto S, Tsukamoto H, Watanabe K, Kirino T (1992) Localization of arachidonate 12-lipoxygenase in canine brain tissues. $\mathrm{J}$ Neurochem 58:1395-1400.

North RA (1989) Drug receptors and the inhibition of nerve cells. $\mathrm{Br}$ J Pharmacol 98:13-28.

O'Dell TJ, Hawkins RD, Kandel ER, Arancio O (1991) Tests of the roles of two diffusible substances in long-term potentiation: evidence 
for nitric oxide as a possible early retrograde messenger. Proc Natl Acad Sci USA 88:1 1285-11289.

Okada D, Yamagishi S, Sugiyama H (1989) Differential effects of phospholipase inhibitors in long-term potentiation in the rat hippocampal mossy fiber synapses and Schaffer/commissural synapses. Neurosci Lett 100:141-146.

Ordway RW, Singer JJ, Walsh JV Jr (1991) Direct regulation of ion channels by fatty acids. Trends Neurosci 14:96-100.

Pace-Asciak CR, Laneuville O, Su W-G, Corey EJ, Gurevich N, Wu P, Carlen PL (1990) A glutathione conjugate of hepoxilin A3: formation and actions in the rat central nervous system. Proc Natl Acad Sci USA 87:3037-3041.

Palmer MR, Mathews WR, Hoffer BJ, Murphy RC (1981) Electrophysiological response of cerebellar Purkinje neurons to leukotriene $\mathrm{D}_{4}$ and $\mathrm{B}_{4}$. J Pharmacol Exp Ther 219:91-96.

Piomelli D, Greengard P (1990) Lipoxygenase metabolites of arachidonic acid in neuronal transmembrane signalling. Trends Pharmacol Sci 11:367-373.

Piomelli D, Greengard P (1991) Bidirectional control of phospholipase A2 activity by $\mathrm{Ca}^{2+} /$ calmodulin-dependent protein kinase II, cAMPdependent protein kinase, and casein kinase II. Proc Natl Acad Sci USA 88:6770-6774.

Piomelli D, Volterra A, Dale N, Siegelbaum SA, Kandel ER, Schwartz $\mathrm{JH}$, Belardetti F (1987a) Lipoxygenase metabolites of arachidonic acid as second messengers for presynaptic inhibition of Aplysia sensory cells. Nature $328: 38-43$.

Piomelli D, Shapiro E, Feinmark SJ, Schwartz JH (1987b) Metabolites of arachidonic acid in the nervous system of Aplysia: possible mediators of synaptic modulation. J Neurosci 7:3675-3686.

Pittman QJ, Siggins GR (1981) Somatostatin hyperpolarizes pyramidal cells in vitro. Brain Res 221:402-408.

Pontzer NJ, Madamba S, Siggins GR, Crews FT (1992) Concentrations of carbachol stimulating phosphoinositide hydrolysis cause a large sustained decrease in membrane potential and firing rate: role of inositol and inositol polyphosphate second messengers. Brain Res 597:189-199.

Samuelsson B, Dahlén S-E, Lindgren JÄ, Rouzer CA, Serhan CN (1987) Leukotrienes and lipoxins: structures, biosynthesis, and biological effects. Science 237:1171-1176.

Sanfeliu C, Hunt A, Patel AJ (1990) Exposure to NMDA increases release of arachidonic acid in primary cultures of rat hippocampal neurons and not in astrocytes. Brain Res 526:241-248.

Schaad NC, Schorderet M, Magistretti PJ (1987) Prostaglandins and the synergism between VIP and noradrenaline in the cerebral cortex. Nature 328:637-640.

Schalling M, Neil A, Terenius I, I indgren $J \AA$, Miamoto T, Hökfelt T,
Samuelsson B (1986) Leukotriene $\mathrm{C}_{4}$ binding sites in the rat central nervous system. Eur J Pharmacol 122:251-257.

Scherer RW, Breitwieser GE (1990) Arachidonic acid metabolites alter $G$ protein-mediated signal transduction in heart. Effects on muscarinic $\mathrm{K}^{+}$channels. J Gen Physiol 96:735-755.

Schonbrunn A (1990) Somatostatin action in pituitary cells involves two independent transduction mechanisms. Metabolism 39[Suppl 2]: 96-100.

Schweitzer P, Madamba S, Siggins GR (1990) Arachidonic acid metabolites as mediators of somatostatin-induced increase of neuronal M-current. Nature 346:464-467.

Shier WT (1979) Activation of high levels of endogenous phospholipase $A_{2}$ in cultured cells. Proc Natl Acad Sci USA 76:195-199.

Shimizu T, Wolfe LS (1990) Arachidonic acid cascade and signal transduction. J Neurochem 55:1-15.

Siggins GR, McGinty JF, Morrison JH, Pittman QJ, Zieglänsberger W, Magistretti P, Gruol DL (1982) The role of neuropeptides in the hippocampal formation. Adv Biochem Psychopharmacol 33:413-422.

Sims SM, Singer JJ, Walsh JV Jr (1988) Antagonistic adrenergicmuscarinic regulation of $\mathbf{M}$ current in smooth muscle cells. Science 239:190-192.

Storm JF (1989) An after-hyperpolarization of medium duration in rat hippocampal pyramidal cells. J Physiol (Lond) 409:171-190.

Twery MJ, Gallagher JP (1989) Somatostatin hyperpolarizes neurons and inhibits spontaneous activity in the rat dorsolateral septal nucleus. Brain Res 497:315-324.

Wang H-L, Bogen C, Reisine T, Dichter M (1989) Somatostatin-14 and somatostatin-28 induce opposite effects on potassium currents in rat neocortical neurons. Proc Natl Acad Sci USA 86:9616-9620.

Wang H-L, Reisine T, Dichter M (1990) Somatostatin-14 and somatostatin-28 inhibit calcium currents in rat neocortical neurons. Neuroscience 38:335-342.

Watson TWJ, Pittman QJ (1988) Pharmacological evidence that somatostatin activates the $M$-current in hippocampal pyramidal neurons. Neurosci Lett 91:172-176.

Williams JH, Bliss TVP (1989) An in vitro study of the effect of lipoxygenase and cyclo-oxygenase inhibitors of arachidonic acid on the induction and maintenance of long-term potentiation in the hippocampus. Neurosci Lett 107:301-306.

Williams JH, Errington ML, Lynch MA, Bliss TVP (1989) Arachidonic acid induces a long-term activity-dependent enhancement of synaptic transmission in the hippocampus. Nature 341:739-742.

Yu SP, Adams PR, Rosen AD (1991) Effect of arachidonic acid pathway inhibitors on calcium regulated $M$ current enhancement. Soc Neurosci Abstr 17:67. 